\title{
LA IMAGEN LEGAL DEL DELINCUENTE IMPUTABLE PELIGROSO: REFLEXIONES A TRAVÉS DE LA LIBERTAD VIGILADA
}

\section{The legal image of the dangerous offender: some insights from the measure of supervised release}

\author{
Dyango Bonsignore Fouquet \\ Universidad de Alicante
}

\begin{abstract}
Resumen: Durante la última década ha aumentado el interés político criminal por expandir la aplicación del criterio de peligrosidad en el Derecho penal español. Esto determinó la introducción de la libertad vigilada con el objetivo expreso de aprehender el riesgo que plantea un nuevo tipo de sujeto jurídico-penal: el delincuente imputable peligroso. El presente trabajo examina detalladamente la evolución de esta medida de seguridad con el fin de extraer las notas características de la construcción de los "peligrosos» efectuada por el legislador. Como objetivo último, se pretende reflexionar sobre la idea de peligrosidad que se encuentra detrás de la plasmación legal y las implicaciones que derivan de ella.
\end{abstract}

Palabras clave: libertad vigilada, peligrosidad, delincuencia sexual, terrorismo, medida de seguridad

Abstract: The last decade has seen a rise in the utilization of the dangerousness criterion in the Spanish criminal law. This determined the introduction of the measure of supervised release as a way to respond against certain types of offenders deemed to still pose a risk to the population at time of release. This paper aims to examine this process in depth with the purpose of extracting some of the features of this group of «dangerous» offenders as defined by the Criminal Code. More generally, 
it aims to gain some insight about which concept of dangerousness lies behind these changes.

Keywords: supervised release, dangerousness, sex offenders, terrorism, safety measures

\section{Introducción}

La peligrosidad criminal ha sido tradicionalmente una idea problemática dentro del pensamiento jurídico penal. Además, puede decirse que lo ha sido a diversos niveles y con una intensidad nada desdeñable, por mucho que el apoyo o el simple interés generado por el concepto haya fluctuado a lo largo del tiempo.

La idea de atribuir a un sujeto un riesgo futuro de comisión de nuevos delitos con motivo de la conducta y/o estilo de vida de que ha hecho prueba en el pasado ha generado siempre una particular incomodidad teórica como resultado de su difícil armonización con los postulados tradicionales del Derecho penal y, con especial énfasis, en aquellos casos en que se ha puesto en contacto con aspectos centrales de la teoría jurídica como lo son la noción de agencia libre o el castigo como respuesta a la culpabilidad por el hecho cometido. Sobre ellos, la idea de peligrosidad incide como una aporía irresoluble, como una oposición absoluta que, cuando trata de ser absorbida por el sistema jurídico, procede automáticamente a transformarlo o, incluso, a deformarlo. Cómo entender la acción de un individuo libre y autodeterminado al tiempo que se defiende una tendencia o inclinación delictiva, o cómo concebir la intervención de un sistema penal del hecho que toma en consideración un pronóstico sobre las acciones futuras de los sujetos y actúa en consecuencia aplicando medidas que atienden fundamentalmente a dicho pronóstico, son algunas de las contradicciones teóricas a las que el concepto jurídico de peligrosidad empuja inexorablemente.

Sin embargo, estas dificultades que algunos podrían considerar meramente conceptuales vienen severamente agravadas por la sombra de las repercusiones prácticas que se asocian a la excesiva confianza en la idea de peligrosidad como guía para la intervención penal. Como es a menudo el caso, la reflexión jurídico penal teórica entra en ebullición cuando se ve enfrentada a implicaciones político criminales que se perciben como nefastas o, al menos, capaces de afectar severamente a la libertad efectiva de aquellos sobre quienes la ley se materializa. En este ámbito, la idea de peligrosidad criminal posee una reverberación práctica de enorme peso, de tal manera que, para muchos, lleva consigo (en sí) el espectro mismo de las peores manifestaciones del Leviatán moderno: el Estado totalitario que selecciona a sus enemigos entre la población al tiempo que los señala como peligrosos para la población. 
Esta breve síntesis permite comprender cómo, a pesar de cíclicas incursiones, la idea de peligrosidad criminal ha sido vista en general con cierto recelo, especialmente conforme el modelo constitucional y democrático se ha asentado en nuestro país tras un pasado tan ilustrativo en relación con lo que nos ocupa. Esta tendencia ha sido, sin embargo, relativamente efímera, pudiendo observarse, desde hace unos años, cambios en el clima general de opinión doctrinal respecto al empleo de la peligrosidad criminal como categoría jurídico penal. Desde hace una década aproximadamente, puede observarse cierto resurgimiento del concepto como tema de discusión aceptable (aunque polémico) en nuestro país, situación que viene a coincidir con lo observado en otros países de nuestro entorno en periodos similares. Esto se corresponde con la aparición de sucesivos legisladores penales crecientemente desacomplejados a la hora de instituir mecanismos destinados a aprehender de manera expresa el "problema» planteado por aquellos autores que siguen considerándose peligrosos cuando la ley establece que su responsabilidad para con la sociedad ha quedado extinguida. A los efectos de nuestro sistema jurídico, el primer paso de nuestro Código Penal en esta dirección se inicia en 2010, marcando una tendencia que permanece en la actualidad.

\section{Las medidas de seguridad postpenitenciarias y el discurso legal sobre la peligrosidad}

El propósito para las siguientes líneas se orienta a indagar sobre la forma en que el legislador construye al delincuente peligroso. Un análisis adecuado de la cuestión no puede, sin embargo, evitar ampliar un tanto el campo de visión para contextualizar la reflexión, especialmente si ha de intentarse alcanzar, a través de la palabra de la ley, una cierta racionalidad de la ley en torno a la temática que nos ocupa. Por este motivo, el trabajo se iniciará con un recorrido abreviado de la trayectoria experimentada por las disposiciones sobre peligrosidad introducidas en nuestro actual Código Penal.

Con objeto de simplificar y no reiterar más allá de lo necesario lo que ya ha sido expuesto dilatadamente por otros autores, se optará por circunscribir el análisis a tres hitos. Estos han sido seleccionados por su valor clave dentro de la breve existencia de la medida de libertad vigilada, que es protagonista de buena parte del análisis, así como (más en general) por su trascendencia a la hora de reflexionar sobre las incursiones efectuadas por el legislador en el terreno del Derecho penal de la peligrosidad. Dos de los hitos seleccionados se corresponden con cambios legislativos efectivos mientras que el tercero (segundo en orden cronológico) se ha seleccionado como síntoma cualificado de un determinado clima regulador o, en otros términos, como indicador de una concreta intención legislativa que, si bien no llegaría a materializarse, resulta altamente 
ilustrativa para encuadrar la reflexión. Este proceso tratará de ahondar en el concepto de peligrosidad (y de criminal peligroso) adoptado por el legislador a través del examen de los instrumentos de que se ha dotado para hacerle frente.

Se partirá de la reforma del Código Penal efectuada a través de la LO 5/2010, tanto por haber actuado como "primer paso» como por suponer el antecedente directo de la actual regulación ${ }^{1}$, que ha preservado la mayoría de lo introducido entonces. A continuación, será examinado con brevedad (no sería posible más que esto en un texto de estas características) el Anteproyecto de reforma del Código Penal propuesto en 2012 y que, circunscribiéndonos a la temática que nos ocupa, propuso la adopción decidida de un modelo de peligrosidad con todas sus letras, con la significativa introducción de la custodia de seguridad. Finalmente, nos detendremos en la actual versión del Código que, tras la puesta al margen de la visión defendida por el Anteproyecto, aparece como una «reforma de mínimos» (SALAT PAISAL, 2015, p. 366) del campo aplicativo de la libertad vigilada respecto al texto del Código que resultó de la reforma de 2010.

La elección de estos indicadores para reflexionar sobre la peligrosidad criminal puede resultar reductora y hasta cierto punto arbitraria. No obstante, se ha preferido emplear un criterio acrítico que toma al pie de la letra al legislador, optando por no ver peligrosidad más allá del más estricto de los sentidos, con el fin de efectuar un examen de la intención del legislador prácticamente según sus propios términos ${ }^{2}$. Así, se ha decidido circunscribir el análisis a aquellos instrumentos jurídico-penales que se presentan a sí mismos como directamente enfocados a responder

1 «Abriendo la brecha», según ACALE SÁNCHEZ (2014, p.27), a las reformas que estaban por venir.

2 Con todo, no se desconoce el hecho sugerido por parte de la doctrina según el cual la peligrosidad criminal ha sido introducida de soslayo en la reflexión y producción legislativa de los últimos años a través de institutos como la reincidencia/multirreincidencia, las reformas de cumplimiento íntegro o, simplemente, el incremento de los marcos penales; todo ello, en cualquier caso, forzando los límites de la responsabilidad por culpa con fines asegurativos. Ver, por ejemplo: la Exposición de Motivos del Anteproyecto de Reforma del Código Penal de 2012 (p.11), o en la doctrina, explícitamente Manso Porto, Molina Blázquez, \& Rodríguez Horcajo (2013), p. 407; así como Armaza Armaza (2013), pp. 167-9; BorJa Jiménez (2012), p.40; CEREzo Mir (2008), p. 21; Jorge Barreiro (2010); Leal Medina (2011), pp. 3-4; Quintero Olivares (2013), p. 658. Tampoco se ignora, por otro lado, que la separación entre punitivismo y prevencionismo puede, en la práctica, ser difícil de deslindar (MARAVER GómEZ, 2015, p. 287; SANZ MORÁN, 2003, pp. 75-77), particularmente cuando la prevención es concebida fundamentalmente como inocuización y, en el proceso, maquillada como justo castigo (RoBles Planas, 2007, p. 4). La ocasional intangibilidad de estas distinciones, muy propias del paradigma jurídico continental, explican posiblemente el hecho de que en el ámbito anglosajón se haya optado tradicionalmente por hablar únicamente de penas, y no de penas y medidas (MARAVER Gómez, 2015, pp. 290-293; VAN Der Wolf, 2016, p. 45).

(C) UNED. Revista de Derecho Penal y Criminología, 3. Época, $n .^{\circ} 20$ (2018) 
a la peligrosidad de un (no tan) nuevo espécimen criminal: el delincuente imputable peligroso ${ }^{3}$.

\section{El resurgir del dualismo. Primeros rasgos del delincuente imputable peligroso en el Código Penal de 2010}

a) La adopción del modelo de doble vía y los motivos del legislador

El nacimiento de la libertad vigilada en nuestro Código Penal se produce por medio de la LO 5/2010 que reforma el mismo. Este es un momento destacado en la medida en que representa un (modesto) cambio de paradigma respecto al modelo de penalidad que había sido adoptado por el legislador penal desde 1995. Así, el sistema jurídico penal español pasa de un sistema que ha sido denominado en ocasiones «nuevo monismo» (ZUGALDÍA ESPINAR, 2009, p. 201), a un sistema de doble vía "puro» ${ }^{4}$. Esto supone pasar de un modelo de penalidad caracterizado por destinar a los sujetos imputables una respuesta única a través del sistema de penas (al tiempo que establece una regulación ad hoc de medidas de seguridad para los sujetos inimputables y semiimputables), a otro cuya propiedad esencial reside en la posibilidad de adjudicar a los sujetos penalmente responsables tanto penas como medidas de seguridad 5 . Esto representa un salto considerable dentro de nuestro contexto jurídico que introduce, sin embargo, lo que para algunos son inquietantes reminiscencias del pensamiento legislativo preconstitucional (a través de la Ley de Vagos y Maleantes y la Ley de Peligrosidad y Rehabilitación Social) ${ }^{6}$, precedente histórico más próximo en lo que al uso de la peligrosidad en imputables adultos ${ }^{7}$ se refiere.

3 Por motivos de claridad expositiva y espacio será obviada la cuestión de los semiimputables e inimputables, si bien algunas referencias sobre cómo se ha visto afectada esta materia en las últimas reformas pueden encontrarse en SALAT PAISAL (2015, pp.328-330).

4 Sobre las delimitaciones conceptuales de la respuesta penal a través de penas y medidas ver, por ejemplo, URRUEla MORA (2003, pp. 31-46).

$5 \mathrm{Si}$ bien, en el terreno de las medidas de seguridad aplicadas a imputables ya contábamos con el ejemplo un tanto sui generis de la expulsión de extranjeros en situación irregular, cuya naturaleza ha resultado siempre confusa aunque sus efectos simbólicos bien podrían aproximarse a los resaltados en el análisis subsiguiente (BLANCO CORDERO y DOVAL PAIS, 2013, pp. 58-60)

6 Al respecto, García Rivas (2013, pp. 605-610). Es necesario tener en cuenta, no obstante, que estos ejemplos normativos permitieron algo que desde entonces no ha vuelto a plantearse seriamente en nuestro Derecho Penal, a saber, hacer uso de un concepto de peligrosidad «social» antes que estrictamente criminal, estableciendo un espacio de indistinción entre lo predelictual y lo posdelictual (SANZ MORÁN, 2003, p. 89)

7 Desde luego el antecedente más inmediato del uso moderno de la medida de libertad vigilada en nuestro ordenamiento puede encontrarse en la legislación penal de menores (LEAL MedinA, 2011, pp. 6-7), si bien su contenido y, sobre todo, su orientación, difieren de la «traducción» efectuada al Derecho penal de adultos (CÁmARA ARROYO, 2012; JimÉnEZ MartíneZ, 2012, p. 18; ManZanares SAMANIEGO, 2010, p. 8). 
Ascendencia normativa y connotaciones aparte, lo cierto es que, como modelo de doble vía, el planteado por el legislador de 2010 es cuando menos comedido, tímido incluso ${ }^{8}$, puesto que se limita a introducir la medida de libertad vigilada con un uso marcadamente restringido. A cierta distancia queda del resto de ordenamientos jurídicos de nuestro entorno a los que se remite el legislador frecuentemente a modo de justificación ${ }^{9}$. Así, en esta primera incursión legislativa la libertad vigilada sólo era susceptible de ser aplicada ante dos supuestos ${ }^{10}$ : terrorismo y delincuencia sexual (ex arts. 192.1 y 579.3 CP). Como consecuencia, cabe ya mantener presente el papel prioritario de estas dos categorías delictivas como representantes de la "peligrosidad» criminal, papel que, como veremos, han conservado hasta la actualidad.

Ahora bien, antes de prestar mayor atención a los pormenores de la regulación introducida por medio de la LO 5/2010, resulta oportuno detenerse brevemente sobre la motivación manifestada por el legislador en el Preámbulo de la misma. Este ejercicio, habitualmente bastante ilustrativo, resulta especialmente interesante cuando se producen cambios de tendencia tan significativos como el que estamos analizando ${ }^{11}$. Y es que buena parte de la trascendencia de este primer acercamiento al terreno del Derecho penal de la peligrosidad no deriva tanto de la concreta opción reguladora adoptada (como veíamos, ciertamente contenida) como del valor simbólico de traspasar una frontera hasta el momento infranqueable. Véase, pues, el siguiente fragmento:

Es notorio, sin embargo, que en determinados supuestos de especial gravedad ese efecto rehabilitador de la pena se ve dificultado, en la medida

8 En términos del propio prelegislador en la Exposición de Motivos del APRCP 2012, p. 9.

9 En este sentido el repertorio es variopinto: Por mencionar solamente el ámbito europeo, sistemas como el del Reino Unido han abordado la cuestión de la peligrosidad desde el monismo a través de las extended sentence o, incluso, formas de prisión de por vida (life sentence) (BEARD, 2017, p. 12). Por otro lado, sistemas dualistas como el suizo, el alemán, el austríaco y, más recientemente, el francés, contemplan sus propias formas de internamiento postpenitenciario a través de medidas de seguridad (Sicherungsverwahrung, rétention de sûreté...), así como formas no privativas de libertad de control de penados (Führungsaufsicht, suivi socio-judiciaire...). Vid. JIMÉNEZ MARTínEZ (2012), pp. 18-22; MANZANAREs SAMANIEgo (2010), pp. 7-8; MARAVER Gómez (2015), pp. 291-295.

10 Esta afirmación merece ser matizada considerablemente y, anticipando lo que luego se dirá, hay que considerar que los «dos supuestos» en que el Código asignaba la imposición de la medida de libertad vigilada implicaba a categorías delictivas enteras, de tal manera que cuando hablamos de "terrorismo" para simplificar, en realidad estamos hablando de todo el espectro de delitos comprendidos dentro del Título XXII, Capítulo VII. Lo mismo puede afirmarse, con más énfasis en la pluralidad tipológica si cabe, respecto de los delitos contra la libertad e indemnidad sexuales, que incluyen todo el Título VIII en virtud de lo dispuesto en el artículo 192 CP.

11 El lector escéptico podría argumentar que el contenido de los Preámbulos o las Exposiciones de motivos contiene, en el mejor de los casos, tanto motivaciones ex ante como racionalizaciones ex post. Sea como fuere, ello no parece desmerecer el interés del examen de tales apartados introductorios de las normas. 
en que ésta no resulta suficiente o adecuada para excluir un elevado riesgo de reincidencia.

La opción inocuizadora, que se traduciría en la prolongación ilimitada y/o indiscriminada de la privación de libertad, choca obviamente con principios elementales del Derecho Penal que la Constitución ampara. Se hace necesario, por tanto, para tales casos de especial gravedad expresamente previstos, contemplar otras soluciones que, sin cejar en el esfuerzo rehabilitador que debe seguir inspirando el tratamiento penitenciario, permitan conciliar las referidas exigencias constitucionales con otros valores no menos dignos de tutela, como son la seguridad y la libertad del resto de los ciudadanos, potenciales víctimas del delincuente no rehabilitado que el sistema penitenciario devuelve a la sociedad. Agotada, pues, la dimensión retributiva de la pena, la peligrosidad subsistente del sujeto halla su respuesta idónea en una medida de seguridad.

Por ello la presente Ley introduce, mediante la modificación parcial y una leve reordenación del Título IV del Libro Primero del Código Penal, una nueva medida denominada libertad vigilada... ${ }^{12}$.

Varias cosas requieren ser señaladas en este fragmento tan cargado de contenido altamente ilustrativo. Globalmente, aquello que trata de proponerse al público con estas líneas es la idea básica de que el sistema penitenciario se encuentra limitado en su capacidad para reinsertar a algunos de sus sujetos, lo cual plantea un problema serio en el momento en que la tutela penal se extingue por la liberación. Para poner remedio a esta situación, por tanto, han debido arbitrarse medios de control apropiados para que, «sin cejar en el esfuerzo rehabilitador», los intereses de la sociedad no sean expuestos a un riesgo que aparece como irrazonable. La libertad vigilada nace, pues, como instrumento al servicio de tales fines.

El problema de la presentación un tanto genérica que nos ofrece el Preámbulo es que no nos explica el porqué de la selección de unos tipos en concreto ni, de hecho, el porqué de la exclusión de tantos otros. Tampoco da pistas sobre de qué modo era necesario el cambio o de dónde proviene esta inquietud que parecen producir al legislador el delincuente no rehabilitado sexual o terrorista. De hecho, para obtener algo más de información resulta necesario acudir al Proyecto de 27 de noviembre de 2009 de reforma del Código Penal ${ }^{13}$, que antecede a la versión comentada del código, y cuya Exposición de Motivos resulta más directa en sus manifestaciones. Así, por ejemplo, el prelegislador explica que los casos en que la pena no "resulta suficiente o adecuada para excluir un elevado riesgo de reincidencia» vienen vinculados a "determinados perfiles criminológicos» caracterizados por su mayor resistencia al efecto rehabi-

12 LO 5/2010, Preámbulo, apartado IV. Cursiva añadida.

13 Ver, sobre el particular, JimÉnEz MARTínez (2012), pp.26-27. 
litador. Con ello se refiere precisamente a los autores de delitos sexuales y terroristas, indicando que, "ya sea porque la inclinación delictiva del sujeto aparece vinculada a determinados trastornos de personalidad o de conducta» (delitos sexuales) o bien porque "su actuar se enmarca en una actitud de indole pretendidamente ideológica que comporta la negación de la condición delictiva misma de su conducta... ${ }^{14}$ (delitos de terrorismo), no cabría esperar en ellos grandes resultados del tratamiento penitenciario. Esta es precisamente la pieza que faltaba (pues fue suprimida) para hacer más inteligible el fragmento del Preámbulo antes presentado, ya que nos ofrece una abertura sobre la imagen que el legislador se ha formado sobre las dos categorías delictivas en las que ha focalizado su «Derecho de peligrosidad».

También reviste interés una reflexión breve, aunque inusualmente atrevida, inserta en un pasaje posterior, en la que el prelegislador reconoce el carácter ya extremadamente elevado de las penas establecidas para los delitos mencionados, especialmente a la vista de las previsiones de cumplimiento íntegro que pueden, en su caso, comportar "resultados prácticos no muy distantes de la cadena perpetua». Con todo, estas observaciones distan de conducir a un atisbo de autocrítica, en la medida en que anteceden y justifican la «necesidad» de "contemplar otras soluciones» ${ }^{15}$, véase, el establecimiento de la libertad vigilada como medida de seguridad postpenitenciaria. Así, implícitamente, asoma de forma entreverada la idea de que seguir interviniendo penalmente en tales casos se mostraba insostenible a través de una nueva extensión de los marcos penales o un nuevo endurecimiento de los regímenes de cumplimiento. Los límites de proporcionalidad por culpa quedan de esta manera marcados como trabas a la eficacia del sistema penal, estandartes de un garantismo que se hace necesario rodear en un claro ejercicio de «contra-ley» $\mathrm{O}$ "contralegislación» ${ }^{16}$.

b) Primera definición del delincuente imputable peligroso y su plasmación legal

Como transición desde el apartado anterior sigamos examinando por un instante más el Preámbulo de la LO 5/2010.

La novedad sustancial que incorpora la libertad vigilada es que resulta aplicable no sólo cuando el pronóstico de peligrosidad del individuo se relaciona con estados patológicos que han determinado su inimputabilidad o semiimputabilidad, sino también cuando la peligrosidad deriva del específico pronóstico del sujeto imputable en relación con la naturaleza del

14 EM PRCP 2009, p. 2

15 EM PRCP 2009, pp. 2-3.

16 Sobre el concepto de counter-law ver: ERICsOn (2007), pp. 24-31. También HeBENTON y SEDDON (2009), pp. 346 y ss.

(C) UNED. Revista de Derecho Penal y Criminología, 3. ${ }^{a}$ Época, $n .^{\circ} 20$ (2018) 
hecho cometido, siempre y cuando el propio legislador así lo haya previsto de manera expresa ${ }^{17}$.

Aquí el legislador plasma su decisión de introducir una nueva figura, un nuevo sujeto penal implícito en la regulación y que, sin ser totalmente distinto respecto al delincuente clásico, no se corresponde perfectamente con él: hablamos del delincuente imputable peligroso. Así, se entiende que este "tipo" de autores son capaces de culpabilidad en sentido tradicional pero, al mismo tiempo, se estima que representan todavía un riesgo para los demás en el momento de su liberación, aunando así dos cualidades jurídicas hasta el momento básicamente separadas: culpabilidad y peligrosidad. En consecuencia, se hacen a su vez compatibles (acumulables) las respuestas penales que les vienen respectivamente adjudicadas, es decir, penas y medidas de seguridad. Sobre esta base se ha asentado la posibilidad de imponer en sentencia una medida de seguridad de libertad vigilada para su cumplimiento una vez cumplida la pena de prisión (GARCÍA RIVAS, 2013, p. 603; SALAT PAISAL, 2015, pp. 325-7), como hemos tenido ocasión de anticipar.

A su vez, este mismo fragmento sirve para adelantar algo que resulta esclarecedor y que será expuesto con mayor detalle más adelante. Obsérvese que el delincuente imputable que ocupa la mente del legislador es de una clase muy específica que no se corresponde tanto con lo que dictaría una concepción positivista de la peligrosidad ${ }^{18}$, sino que más bien aparece como una identidad normativamente determinada. Esto se deduce de observar cómo decidió el legislador regular la imposición de la libertad vigilada en estos dos supuestos: en ambos casos, su imposición en sentencia es imperativa ${ }^{19}$, es decir, no condicionada por un diagnóstico/pronóstico, sino asignada conforme a lo que aparece como una presunción iuris et de iure de peligrosidad ${ }^{20}$ cuya única modulación procede de la gravedad del delito o de la pena impuesta (según se trate de delincuencia sexual o terrorismo). Este inciso permite resaltar que en el pasaje anteriormente citado del Preámbulo el legislador no comete un

17 LO 5/2010, Preámbulo, apartado IV.

18 Se haya aludido o no a la idea de «perfiles criminológicos» en algún momento, lo cierto es que una regulación que hubiese pretendido inspirarse en los postulados del positivismo criminológico (en su versión contemporánea o en el sentido clásico de la escuela italiana) hubiera debido contemplar, como mínimo, el papel protagónico de lo que la doctrina suele denominar «diagnóstico y pronóstico» de peligrosidad criminal. En su lugar, la opción adoptada por el legislador establece como elemento esencial la «familia» delictiva en que se inserta el autor. Para una visión sintética pero clarificadora sobre la dirección adoptada por la criminología en materia de riesgo ANDRÉs-PuEYo (2013).

19 Ver artículos 192 y 579 bis CP, donde se observa que «se les impondrá además la medida de libertad vigilada».

20 Al respecto ver: Navarro Frías (2011), p. 130; Salat Paisal (2015), p. 330. El argumento opuesto (quizás más en la forma que en el fondo) puede encontrarse en OTERO GoNZÁLEZ (2015) 
desliz de redacción sino que, muy al contrario, establece con total claridad el concepto de peligrosidad de que va a hacer uso: una peligrosidad que procede de un pronóstico (implícito) directamente vinculado a la naturaleza del hecho.

Este régimen con carácter de imperativo legal de directa aplicación ha de ser matizado desde este momento a través de dos detalles que provocan que los efectos de esta presunción vengan atenuados de manera un tanto contraintuitiva. En primer lugar, a través de la posibilidad establecida en los apartados 2 y 3 del artículo $106 \mathrm{CP}$, que permiten modular o dejar sin efecto la medida impuesta antes de que ésta llegue a ejecutarse, en virtud del procedimiento establecido en el artículo $98 \mathrm{CP}$. Así, lo que es imperativo (en fase de sentencia) debido a la naturaleza del hecho, acaba siendo facultativo una vez cumplida la pena de prisión, en caso de darse las condiciones establecidas ${ }^{21}$.

Otra excepción al régimen (cuasi)automático mencionado se encuentra en lo que podríamos llamar la «cláusula de delincuente primario», que establece que, en cualquiera de los dos casos anteriores, será potestativo imponer en sentencia la medida de libertad vigilada siempre que a) se trate de un único delito, b) el delito cometido no fuera grave y c) el delincuente fuera primario (arts. 192 y 579 bis CP). En tales casos el legislador apostilla que se atenderá a su «menor peligrosidad» a la hora de decidir sobre la imposición o no de la medida en fase de sentencia. Al respecto, parece peculiar que el espacio creado para una valoración individual fuera reservado, en la LO 5/2010, a los casos en que resultara posible no imponer la medida por encontrarse en la parte baja del espectro de gravedad. Esto otorga a la valoración de la peligrosidad un aspecto marcadamente instrumental destinado a justificar sólidamente aquellas decisiones que puedan conducir a no imponer la medida de seguridad y asumir, en el proceso, el riesgo potencial de reincidencia ${ }^{22}$.

A la vista queda la concepción del legislador: los terroristas y los delincuentes sexuales no son peligrosos con motivo del riesgo individualizado de reincidencia que representan (lo cual implicaría situar todo o buena parte del peso de la peligrosidad sobre el diagnóstico/ pronóstico de la misma), sino que lo son porque así se deriva de la

21 Desde luego, no debería extrañar que haya quedado abierta la puerta para modificar o dejar sin efecto la medida en este segundo momento, pues armoniza bien con fin resocializador de las penas y del tratamiento penitenciario.

22 Similarmente, Robles PlanAs, (2007): "En cierta medida puede afirmarse que la rudimentaria noción de la peligrosidad criminal (y de los inseguros criterios para su determinación individual) se ha quedado anticuada para fundamentar la reacción penal. Más bien la tendencia parece ser la de que sólo la garantía de no peligrosidad impide la intervención coactiva. La suficiente seguridad sólo queda garantizada si la puesta en libertad del autor sólo acontece cuando no exista ningún riesgo (más) de reincidencia.»(p.15). 
tipología delictiva a la que pertenecen ${ }^{23}$. El criterio es pues de origen normativo en tanto que es isomorfo con las categorías ${ }^{24}$ empleadas en la legislación y se remite directamente a las mismas sin intermediarios. Es la naturaleza del hecho la que motiva al legislador, quien atribuye a priori la etiqueta de potencialmente peligrosos a los autores de delitos incluidos en dos de los «compartimentos» que sirven para organizar el Código Penal.

Esto contribuye a lo alienante de la técnica legislativa empleada ${ }^{25}$. En lugar de implantar un modelo «clásico» de derecho penal de la peligrosidad, donde esta última viene referida al autor concreto y en el que cualquiera puede representar un riesgo criminal con relativa independencia del hecho que haya cometido originariamente ${ }^{26}$, el legislador ha optado por orientar selectivamente su atención a dos subgrupos de delincuencia. Y esto además de manera indiferenciada, determinando que es la categoría a la que pertenecen (el bien jurídico contra el que atentan, grosso modo) lo que constituye o revela su peligrosidad. Por este motivo, todos y cada uno de los tipos que vienen a quedar englobados dentro de los delitos de terrorismo (Título XXII, Capítulo VII) y los delitos contra la libertad e indemnidad sexuales (Título VIII) son igualmente merecedores de la imposición de la medida de libertad vigilada. Así, lo que en un principio podría aparecer como un criterio de empleo restrictivo de la peligrosidad (reservándola para delitos muy singulares y limitados), acaba actuando de manera extensiva en el interior de cada una de estas familias típicas. Una contradicción aparente que puede sin embargo resultar ilustrativa sobre cómo es concebido el delincuente peligroso en nuestro ordenamiento: un sujeto "marcado» por haber transgredido unos límites infranqueables, incorporado por ello a la categoría de peligroso con independencia de la severidad de su afrenta ${ }^{27}$.

En vista de lo anterior, difícilmente podríamos entender que esta primera incursión de nuestro Código Penal en el terreno del Derecho de la peligrosidad suponga un acercamiento notorio a los criterios «criminológicos» que tanta suspicacia producen en parte de la doctrina. Más bien

23 Categorías de autores y delitos muy «fotogénicos» indica apropiadamente AcAlE SÁNCHEZ (2014), p. 24.

24 Similar criterio «categorial» es el que detecta Murphy (2008), p.1333.

25 También parecen extrañados, en ocasiones por motivos diferentes, autores como: Jiménez Martínez (2012), p. 28; Navarro Frías (2011), pp. 130-131; SAlat Paisal (2015), p. 330; SANZ MoRÁn (2011), pp. 1019-1020.

26 Pues el concepto de peligrosidad criminal, en su más radical expresión, no obliga a distinguir por tipos de delitos en la medida en que estos son vistos frecuentemente como meros "síntomas» o formas coyunturales de expresar ese riesgo subyacente (GARCíA-PABLOS DE Molina, 2014, p. 452).

27 Con la reforma de 2015, como veremos, este análisis no pierde validez, pero viene complementado por la inclusión de otras figuras de peligrosidad que se rigen de un modo algo distinto. 
al contrario, el legislador demuestra que tales consideraciones resultan ampliamente prescindibles (al menos en el momento de la conminación legal) e introduce una regulación que poco o nada tiene que ver con castigar al autor por quien es en lugar de por lo que ha hecho. Si acaso, la persona que es viene inferida del hecho que ha cometido, sustituyendo el afán individualizador por la mera subsunción de los autores dentro de colectivos de riesgo ${ }^{28}$, adjudicatarios de peligrosidad para quienes se prevé una respuesta indiferenciada.

c) Breve anticipo de la regulación de la libertad vigilada y remisión

Correspondería ahora adentrarse algo más en el contenido de la medida de libertad vigilada, sin embargo, dado que el legislador de 2015 conservó lo establecido en 2010 prácticamente intacto, en el presente texto, se ha optado por desplazar el grueso de este examen a una sección posterior. Sin embargo, resulta necesario a objetos expositivos dar siquiera algunas pinceladas sobre qué fue lo que introdujo el legislador de 2010 cuando creó la medida de seguridad de libertad vigilada.

Condensando enormemente, la libertad vigilada cristaliza como una medida de seguridad no privativa de libertad ${ }^{29}$ cuyo núcleo esencial viene definido por la imposición de una o más obligaciones, prohibiciones y reglas de conducta de entre las específicamente indicadas en el artículo 106.1 CP. En ausencia de criterios para la determinación del contenido de la medida, el margen para la variabilidad de un caso a otro es más que considerable, de suerte que, en términos de SALAT PAISAL (2016), "cada una de las distintas medidas de libertad vigilada impuestas a diferentes sujetos puede fácilmente no tener nada que ver con las otras» (pp. 164-5).

Su imposición se decreta en sentencia para su cumplimiento con posterioridad a la pena de prisión, siendo, como hemos visto, acumulativa a la misma (art. $105 \mathrm{CP}$ ). Ello se corresponde con la intención del legislador de instituir un mecanismo apropiado para gestionar la peligrosidad de los sujetos «no rehabilitados» en el momento de su liberación. Por último, la duración de la medida, para imputables, puede alcanzar los diez años, duplicando en este caso lo establecido para inimputables y semiimputables (SALAT PAISAL, 2015, p. 336).

\footnotetext{
28 A la vista de que el riesgo atribuido a tales colectivos no es examinado ni justificado de ninguna forma particular, podría estar justificado hablar incluso de «grupos de riesgo presunto o putativo».

29 Si bien durante su turbulento íter legislativo adoptaría inicialmente la forma de pena (Martínez Garay, 2014, pp. 6-7; Salat Paisal, 2015, pp. 302-324; Urruela Mora, 2015, p.126).
} 


\section{El Anteproyecto de 2012 y el Derecho penal de la peligrosidad que no pudo ser}

a) El Anteproyecto como ensayo de una auténtica penalidad de doble vía

Aunque el análisis del Anteproyecto de 2012 requeriría un espacio mucho más dilatado, a los efectos de este texto prestaremos atención únicamente a una de sus medidas «estrella», la custodia de seguridad ${ }^{30}$, así como a las modificaciones introducidas a la libertad vigilada en tanto que sean relevantes para nuestros intereses. En ambos casos se atenderá especialmente a la redefinición de los límites abarcados por el concepto de delincuente imputable peligroso, así como a los rasgos fundamentales del instrumental jurídico propuesto para hacerle frente.

A modo de contexto, cabe decir que el Anteproyecto de Reforma del Código Penal de 11 de octubre de 2012 supuso por «méritos» propios un hito dentro de la producción legislativa de los últimos años. Y no solo por la envergadura de la propuesta, sino por el tipo de cambios puestos sobre la mesa. El que focaliza nuestro interés sería, seguramente, el más perturbador para el estado de cosas jurídico penal, si no fuera por la introducción simultánea de la prisión permanente revisable, ambos puntos clave de un Anteproyecto de tono más bien hosco. Con todo, aquí nos restringiremos al estudio somero de los cambios propuestos para el sistema de medidas de seguridad y, en particular, a aquellos destinados, en palabras del prelegislador, a culminar la evolución iniciada por la LO $5 / 2010$ con «la definitiva consagración de un sistema dualista» ${ }^{31}$.

Para servir a tal propósito, se arbitran dos grandes modificaciones: por un lado, la introducción de la custodia de seguridad como forma de internamiento postpenitenciario sustentado en la peligrosidad; por otro, la drástica expansión del campo de aplicabilidad de la medida de libertad vigilada. En ambos casos, queda consagrada legalmente, ya sin «timidez», la figura del delincuente imputable peligroso a través de la emancipación del criterio de peligrosidad respecto del de culpabilidad ${ }^{32}$ por medio de la reforma del apartado segundo del artículo 6, que pasa a vincular las medidas de seguridad en exclusiva a la peligrosidad apreciada en el sujeto ${ }^{33}$, reforma que caracteriza el movimiento efectuado por el

30 Si bien algo merecería ser dicho, dentro del terreno que nos ocupa, sobre la prisión permanente revisable que, a diferencia de la custodia, sí encontraría su lugar en el texto legal definitivo.

31 EM APRCP 2012, p. 9.

32 En la EM APRCP 2012: "Estas medidas de seguridad se fijarán en proporción a la peligrosidad del autor, de modo que no estará limitada en su extensión por la duración de la pena prevista para el delito cometido»(p.11).

33 Artículo 6.2 del APRCP 2012: "Las medidas de seguridad no podrán exceder el límite de lo necesario para prevenir la peligrosidad del autor». 
prelegislador en su intención de aproximarse a una autonomización ${ }^{34}$ de la peligrosidad como criterio de uso jurídico penal más cercano al autor y su idiosincrasia que al hecho y sus circunstancias ${ }^{35}$.

b) Sobre la custodia de seguridad

La custodia de seguridad resulta a estas alturas bien conocida en la discusión jurídica, siquiera en sus fundamentos, que son los que nos interesan ${ }^{36}$. A modo de breve recapitulación, nos encontramos ante una medida de seguridad privativa de libertad que adopta la forma de un internamiento, ya sea en centros especiales o, en su caso, en los mismos centros penitenciarios (art. 101.4 APRCP). Su ejecución da comienzo una vez cumplida la pena de prisión derivada de la comisión de un delito, dado que el propósito de este mecanismo parte de la neutralización de aquellos sujetos que siguen considerándose altamente peligrosos en el momento en que ha de concederse la liberación. La medida, tal como se concibió, estaba sujeta a revisiones periódicas (de hasta 2 años de intervalo) ${ }^{37}$, y podía extenderse hasta los 10 años de duración, teniendo asignada una medida de libertad vigilada (de hasta 5 años más) para su cumplimiento una vez suspendida ${ }^{38}$ o extinta la custodia (arts. $101.6 \mathrm{y}$ 102.3 APRCP).

34 Así lo expresa Acale SÁNchez (2013): «Si, como hace el Anteproyecto, se elimina del art. 6.2 el limite de la medida de seguridad en atención al hecho cometido, se des-objetiviza la responsabilidad y se pone en manos exclusivamente de la peligrosidad del autor...» (p. 416).

35 Incluso en los casos en que la peligrosidad se ha querido deducir de las circunstancias del hecho cometido, ello no deja de ser más expresión de una preocupación garantista con los límites de la intervención punitiva del Estado antes que un planteamiento de fondo sobre la peligrosidad criminal. Así, cuando se deduce peligrosidad de elementos objetivos vinculados al hecho (como la forma comisiva, la repetición, o hasta el tipo), lo que se hace es usar estos como indicios sobre los cuales estructurar una inferencia de peligrosidad. Pero esta peligrosidad no puede ser del hecho en sí, en la medida en que ese último tipo de riesgo/peligro es coextensivo con el delito: deja de existir cuando cesa éste (consumado o no). Así, incluso cuando se basa en elementos que circundan el hecho, lo que se dice en el fondo es: las personas capaces de cometer delitos con determinadas características presentan una inclinación a reincidir superior a lo normal o, incluso, lo considerado aceptable.

36 Ver, por ejemplo: Acale Sánchez et al. (2013); Borja Jiménez (2012); Gracia Martín (2008); Manso Porto et al. (2013); Nistal Burón (2013); Roig Torres (2015), pp. 366-396; SÁNCHEZ LÁZARo (2004); Silva SÁNCHEZ (2001), pp. 706-707, (2010).

37 Este plazo de revisión de 2 años se antoja excesivo, casi como una suerte de presunción de la difícil (cuando no imposible) recuperación de los sujetos sometidos a esta medida. Tampoco parece adecuado el empleo de intervalos tan amplios por la tensión que traslada no sólo sobre el reo, sino sobre el organismo que ha de decidir sobre el mantenimiento de la reclusión. Ver a este respecto la propuesta elaborada en MANSO PORTO et al. (2013).

38 Llamativo es, a este respecto, que el prelegislador asumiera la posibilidad de suspender la aplicación de la medida de custodia de seguridad por no existir ya las circunstancias que justificaron su imposición (es decir, la peligrosidad del reo, en tanto que el resto de factores no resultan modificables) y, sin embargo, incorpore en tales casos la 
Sus destinatarios, por tanto, son sujetos imputables que se entiende que representan un riesgo de suficiente entidad para el resto de la sociedad como para justificar la adopción de esta medida, motivo por el cual el pronóstico sobre dicho riesgo tiende a aparecer como un pilar fundamental de la regulación. A pesar del carácter excepcional que se pretendía adscribir a la medida ${ }^{39}$, el elenco de categorías delictivas a las que se propuso hacerla aplicable es considerablemente amplio y heterogéneo: delitos contra la vida, integridad física, libertad, libertad o indemnidad sexuales, los cometidos con violencia o intimidación (incluso siendo patrimoniales), contra la comunidad internacional, de riesgo catastrófico o incendio y, por supuesto, delitos de terrorismo. Finalmente, otro elemento que queda delineado si se examina el artículo 101 APRCP, es el de la pluralidad delictiva (simultánea o diferida en el tiempo) ${ }^{40}$.

La controversia (cuando no directamente repulsa, en ciertos casos) que esta propuesta generaría no es anecdótica, habiéndose señalado como motivos el carácter materialmente punitivo, meramente inocuizador y drásticamente desproporcionado en atención al tipo de intervención penal que queda legitimada (ACALE SÁNCHEZ et al., 2013; MANSO PORTO, MOLINA BLAZZUEZ, y RODRÍGUEZ HORCAJO, 2013). Por no mencionar, además, los serios problemas que plantea un sistema en que pena y medida de seguridad privativas de libertad pueden acumularse sin distinguirse de manera suficientemente sustancial como para evadir la ya habitual crítica del fraude de etiquetas ${ }^{41}$ o el riesgo para el non bis in idem ${ }^{42}$.

imperativa imposición de una medida de libertad vigilada en su lugar (¿a un sujeto no peligroso?). Ver sobre ello los apartados 3 y 4 del artículo 102 del Anteproyecto, así como ROIG TORRES (2015), p. 385.

39 EM APRCP 2012, p.12.

40 Este ha sido criterio de frecuente incorporación a las leyes de peligrosidad, especialmente cuando hablamos de repetición o reincidencia, en tanto que funciona como indicador «fáctico» de una inclinación delictiva que evidencia un riesgo sobre el que intervenir a través de medidas asegurativas de una u otra índole. De hecho, bien podría ser que la idea de repetición delictiva antecediera a la de gravedad o violencia en la caracterización legal de los peligrosos (PRATT, 1997, pp. 8-11).

41 Fraude que, por otra parte, se podría decir que circula en los dos sentidos: penas que actúan como medidas (es decir, que ponderan implícitamente la peligrosidad), y medidas que actúan como penas (esto es, aquellas que cristalizan en una mera segunda punición, una "prisión postpenitenciaria») apoyándose en una teorizada diferencia de fundamentos entre pena y medida que, en la práctica, no resulta tan fácil de discernir (AcALE SÁNCHEZ et al., 2013, p. 399; MANSO PORTO et al., 2013, p. 408)

42 Riesgo del que el prelegislador es plenamente consciente y así lo recalca desde la Exposición de Motivos, si bien pretende salir al paso con holgura del problema aludiendo al diferente fundamento de la pena y de la medida: "Por esta razón, todos los delitos tienen o deberían tener como consecuencia una pena ajustada a la culpabilidad por el hecho, mientras que las medidas de seguridad solamente son necesarias cuando exista una peligrosidad relevante. Esta diferenciación entre pena y medida de seguridad permite que ambas puedan ser impuestas conjuntamente sin que se produzca una infracción del principio non bis in idem». 
Y aunque, visto lo visto, está claro que quedaba poco espacio para la duda sobre la intención del prelegislador de establecer definitivamente un modelo de doble vía para el Derecho penal español, se ha observado acertadamente que, teniendo en cuenta que la cuestión de la peligrosidad criminal había sido, desde el Código del 95, aprehendida de manera más o menos manifiesta haciendo uso de los mecanismos disponibles en un modelo monista, el cambio al paradigma de doble vía hubiera debido implicar una correlativa reforma a fondo del sistema existente y, especialmente, una reducción drástica de las penas con el fin de acomodarlas al nuevo planteamiento (MANSO PORTO et al., 2013, pp 407-408). En este punto el legislador, incluso cuando se muestra más ambicioso, no alcanza a ser consecuente con las implicaciones derivadas de un cambio tan radical como el que propone, negándose a sacrificar los recursos disponibles en materia de castigo (como exigiría una transición monismo-dualismo instruida por la proporcionalidad) y limitándose a superponer una arquitectura nueva de medidas de seguridad, soslayando así (entre otros) el riesgo mediático que entrañaría una aparente «despenalización» con muchas posibilidades de ser mal comprendida por la opinión pública ${ }^{43}$.

c) Sobre la expansión de la libertad vigilada

En coherencia con la amplitud otorgada a la custodia de seguridad, la libertad vigilada se expande notablemente en este Anteproyecto, pasando a abarcar bajo su manto: homicidio y asesinato, malos tratos de obra en el ámbito familiar, detenciones ilegales y secuestros, trata de seres humanos, hurtos, robos, extorsión, robo y hurto de uso de vehículos de motor, receptación y blanqueo de capitales, delitos contra los ciudadanos extranjeros, estafas, delitos contra la seguridad vial o terrorismo (sin contar aquellos casos en que, como hemos visto, se impone con posterioridad a una medida de custodia de seguridad). En suma, afecta a la mayoría de la delincuencia (MARTÍNEZ GARAY, 2014, p. 288; SERRANO GÓMEZ, 2013, p. 10), especialmente a la vista del requisito de que el sujeto haya sido condenado, como mínimo, a una pena superior a un año de prisión (art. 104 APRCP). Eso sí, en todos los casos menos en terrorismo se pasa a contemplar como una medida potestativa ${ }^{44}$, vinculada a la apreciación de peligrosidad, y no puede ser impuesta fuera de estos supuestos legalmente tasados.

Por lo demás, seguimos ante una medida que consiste en una pluralidad (ampliada en el Anteproyecto) de obligaciones, prohibiciones y

43 Este razonamiento cobra un peso especial si se inserta dentro del contexto jurídico político concomitante a este periodo (BORJA JIMÉNEZ, 2012, pp. 2-20; RoBles PlANAS, 2007, pp. 14-21). Más en general, ver también DíEz Ripollés (2005), pp. 14-22; PratT (1997), pp. 183-184; SILVA SÁNCHEZ (2006), pp. 20-82.

44 El régimen de excepcionalidad de la legislación antiterrorista se extiende nuevamente a lo que, por lo demás, consistía un cambio en la dirección adecuada. 
reglas en general que recaen sobre el sujeto liberado y condicionan su vida en sociedad. Por lo que respecta a su régimen de cumplimiento, el APRCP 2012 establecía que la libertad vigilada tendría una duración mínima de 3 años y máxima de 5, eso sí, prorrogables por plazos sucesivos de hasta 5 años cada uno en determinados supuestos ${ }^{45}$.

Con todo (y a diferencia de lo que se puede en general afirmar en relación con la custodia de seguridad) la acogida de la libertad vigilada por parte de la doctrina, ya sea en sus primeras formulaciones o en su forma actual, ha sido más irregular y divisiva ${ }^{46}$. Esta pluralidad de criterios es comprensible a la vista del carácter complejo y en ocasiones incluso confuso del criterio regulador adoptado. Y es que si hay algo que parece razonablemente claro es que la medida descrita puede llegar a ser casi cualquier cosa, siendo más fácil definirla en negativo, en base a lo que no puede ser.

\section{El Código Penal actual. La libertad vigilada como eje del discurso sobre la peligrosidad}

a) Aspectos generales de la libertad vigilada

A pesar de lo expuesto, los planes del prelegislador no terminaron de concretarse conforme a las previsiones que se hacían evidentes en su Anteproyecto. El enfoque tan decididamente dirigido a instaurar un

45 Algunas reflexiones de cierre sobre el APCP antes de pasar a otra cosa... Así el artículo 104 ter APRCP:

"1.-La libertad vigilada tendrá una duración mínima de tres años y una duración máxima de cinco.

2.-El plazo máximo de duración podrá ser prorrogado por plazos sucesivos de una duración máxima de cinco años cada uno de ellos, cuando se hubieran producido anteriormente incumplimientos relevantes de las obligaciones y condiciones impuestas conforme al artículo 104 bis de los que puedan derivarse indicios que evidencien un riesgo relevante de comisión futura de nuevos delitos, y además: a) La medida de libertad vigilada hubiera sido impuesta en los supuestos del artículo 192.1 de este Código, o, b) de conformidad con lo dispuesto en la letra c) del artículo 103.1 de este Código.

3.-L L libertad vigilada comienza con la firmeza de la sentencia que la impone, en el caso del artículo 104.1 y de la letra a) del artículo 104.2 de este Código, o con la resolución en que se acuerda la suspensión de otra medida de seguridad privativa de libertad, en los demás casos. No se computará como plazo de cumplimiento aquél en el que el sujeto a la medida se hubiera mantenido en situación de rebeldía.»

46 Así, la libertad vigilada ha sido descrita como: «absolutamente imprescindible» (Zugaldía Espinar, 2013, p. 481), de similar tono Leal MEdina (2011, p. 6), entendiéndola como insuficiente Manzanares SAMANiEgo (2010, p. 1), también desde otro punto de vista NAVArro Frías (2011).Por otro lado, entendiendo la introducción de la medida como expresión de un Derecho penal de la seguridad, Maraver Gómez (2015, pp. 305 y ss.), también críticos Acale SÁnchez (2013, pp. 433-435), Benítez Ortúzar (2011), Huerta Tocildo (2013, p.136) o Martínez Garay (2014, pp. 64 y ss.) entre otros. 
modelo de derecho penal de la peligrosidad finalmente no llegaría a materializarse o, al menos, no con la extensión prevista. La custodia de seguridad no sobreviviría el paso al Proyecto de 2013 y, finalmente, el régimen jurídico de la libertad vigilada quedaría tan poco alterado que resulta más sencillo entender el Derecho vigente como directa continuación de la línea marcada por la reforma de 2010 antes que tratar de establecer conexiones genéticas con el Anteproyecto (y, coextensivamente, el Proyecto). Ambos textos prelegislativos han quedado, en relación con la materia que nos ocupa, como desiderata, si bien ello quizás haya sido al precio de incorporar al ordenamiento la prisión permanente revisable, que aparece así como una línea de "progreso» más viable en nuestra cultura jurídica que la asunción de un (mal planteado, eso sí) sistema de doble vía à part entière.

Así las cosas, pasaremos a volcar nuestra atención, por último, sobre la regulación consolidada en el CP actualmente vigente con el objetivo de examinar qué es lo que queda del delincuente imputable peligroso. Con idéntica ocasión se tratará completar el análisis incorporando aquellos aspectos soslayados en el apartado inicial, subrayando a su vez los (escasos) cambios experimentados por la medida de libertad vigilada, que emerge de nuevo como el único mecanismo jurídico penal representante del giro hacia un sistema de doble vía.

Como hemos visto, la medida de libertad vigilada se materializa a través la imposición de una o varias reglas de conducta sobre el condenado que accede a la libertad tras el cumplimiento de una pena de prisión. Esto puede implicar la efectiva vigilancia del sujeto a través de medios electrónicos, aunque es cierto que tampoco tiene por qué ser el caso dado el amplio margen de maniobra que se ofrece en la determinación del régimen de cumplimiento. La enumeración de dichas reglas aparece inalterada desde la reforma de $2010^{47}$, motivo por el que se ha aplazado parte del análisis a este momento de la exposición. Al respecto,

47 Así, el artículo $106 \mathrm{CP}$ establece:

1. La libertad vigilada consistirá en el sometimiento del condenado a control judicial a través del cumplimiento por su parte de alguna o algunas de las siguientes medidas: a) La obligación de estar siempre localizable mediante aparatos electrónicos que permitan su seguimiento permanente. b) La obligación de presentarse periódicamente en el lugar que el Juez o Tribunal establezca. c) La de comunicar inmediatamente, en el plazo máximo y por el medio que el Juez o Tribunal señale a tal efecto, cada cambio del lugar de residencia o del lugar o puesto de trabajo. d) La prohibición de ausentarse del lugar donde resida o de un determinado territorio sin autorización del Juez o Tribunal. e) La prohibición de aproximarse a la víctima, o a aquellos de sus familiares u otras personas que determine el Juez o Tribunal. f) La prohibición de comunicarse con la víctima, o con aquellos de sus familiares $u$ otras personas que determine el Juez o Tribunal. g) La prohibición de acudir a determinados territorios, lugares o establecimientos. h) La prohibición de residir en determinados lugares. i) La prohibición de desempeñar determinadas actividades que puedan ofrecerle o facilitarle la ocasión para cometer hechos delictivos de similar naturaleza. j) La obligación de participar en programas formativos, laborales, culturales, de educación sexual u otros similares.

(C) UNED. Revista de Derecho Penal y Criminología, 3. Época, $n .^{\circ} 20$ (2018) 
la literatura ha tendido a separar las obligaciones y prohibiciones en dos o tres grandes grupos tratando de atender a la principal característica o finalidad de cada una de las medidas contempladas. Uno de los modelos de clasificación propuestos separa entre medidas de vigilancia y control, de protección a terceros o de reinserción/corrección (SALAT PAISAL, 2016, p. 165). La minoría que estas últimas representan frente al resto ha propiciado la caracterización de la libertad vigilada como fundamentalmente inocuizadora algo que, por otro lado, ya anticipaba la elección del término «libertad vigilada» en lugar de otras opciones (más o menos eufemísticas) como supervisada, asistida o similares ${ }^{48}$.

Por lo demás, el grueso de la regulación de la medida sigue fundamentalmente inalterado frente a lo establecido en 2010, pudiendo extenderse su cumplimiento por un periodo de hasta cinco años en términos generales y, en determinados supuestos, hasta diez para la delincuencia sexual o terrorista (ver artículos 105, 192.1 y $579.3 \mathrm{CP}$ ). De hecho, la única modificación introducida en esta última revisión del Código Penal

k) La obligación de seguir tratamiento médico externo, o de someterse a un control médico periódico.

2. Sin perjuicio de lo dispuesto en el artículo 105, el Juez o Tribunal deberá imponer en la sentencia la medida de libertad vigilada para su cumplimiento posterior a la pena privativa de libertad impuesta siempre que así lo disponga de manera expresa este Código. En estos casos, al menos dos meses antes de la extinción de la pena privativa de libertad, de modo que la medida de libertad vigilada pueda iniciarse en ese mismo momento, el Juez de Vigilancia Penitenciaria, por el procedimiento previsto en el artículo 98, elevará la oportuna propuesta al Juez o Tribunal sentenciador, que, con arreglo a dicho procedimiento, concretará, sin perjuicio de lo establecido en el artículo 97, el contenido de la medida fijando las obligaciones o prohibiciones enumeradas en el apartado 1 de este artículo que habrá de observar el condenado. Si éste lo hubiera sido a varias penas privativas de libertad que deba cumplir sucesivamente, lo dispuesto en el párrafo anterior se entenderá referido al momento en que concluya el cumplimiento de todas ellas. Asimismo, el penado a quien se hubiere impuesto por diversos delitos otras tantas medidas de libertad vigilada que, dado el contenido de las obligaciones o prohibiciones establecidas, no pudieran ser ejecutadas simultáneamente, las cumplirá de manera sucesiva, sin perjuicio de que el Juez o Tribunal pueda ejercer las facultades que le atribuye el apartado siguiente.

3. Por el mismo procedimiento del artículo 98, el Juez o Tribunal podrá: a) Modificar en lo sucesivo las obligaciones y prohibiciones impuestas. b) Reducir la duración de la libertad vigilada o incluso poner fin a la misma en vista del pronóstico positivo de reinserción que considere innecesaria o contraproducente la continuidad de las obligaciones o prohibiciones impuestas. c) Dejar sin efecto la medida cuando la circunstancia descrita en la letra anterior se dé en el momento de concreción de las medidas que se regula en el número 2 del presente artículo.

4. En caso de incumplimiento de una o varias obligaciones el Juez o Tribunal, a la vista de las circunstancias concurrentes y por el mismo procedimiento indicado en los números anteriores, podrá modificar las obligaciones o prohibiciones impuestas. Si el incumplimiento fuera reiterado o grave, revelador de la voluntad de no someterse a las obligaciones o prohibiciones impuestas, el Juez deducirá, además, testimonio por un presunto delito del artículo 468 de este Código.

48 Similarmente, Martínez Garay (2014), p. 17.

(C) UNED. Revista de Derecho Penal y Criminología, 3. ${ }^{a}$ Época, n. ${ }^{\circ} 20$ (2018) 
ha sido la incorporación de tres nuevos supuestos a los que aplicar la medida, como veremos en el siguiente apartado.

b) Nuevos supuestos de aplicación

Como decíamos, allí donde la regulación actual sí difiere de lo planteado por la LO 5/2010 es en lo que respecta a los supuestos en los que resulta posible imponer una medida de libertad vigilada, así como el régimen diseñado para los mismos. Así, en primer lugar, al dúo conformado por los delitos de terrorismo y los de carácter sexual, se añaden en la LO 1/2015 tres nuevas figuras: los delitos de homicidio (y sus formas, de acuerdo con el artículo 140 bis CP), las lesiones (ex 156 ter CP) cometidas sobre las personas indicadas en el artículo $173.2 \mathrm{CP}$ (cónyuge, ex cónyuge, ascendientes, descendientes, etc.), y los casos de maltrato habitual (173.2 in fine $\mathrm{CP}$ ). Esto es un paso significativo en la dirección de ampliar la aplicabilidad práctica de la medida, fundamentalmente debido a las dos últimas inclusiones, aunque palidezca si uno ha de considerar como precedente el Anteproyecto de 2012.

Un segundo detalle significativo de este addendum legislativo radica en la previsión, desde el principio, de la imposición de la libertad vigilada como una potestad del órgano sentenciador ${ }^{49}$. Así, en estos tres casos, la imposición en sentencia de la medida deviene facultativa, pasando a estar vinculada mucho más estrechamente a una valoración individualizada. Esto bien podría ser una respuesta a las críticas recibidas con ocasión de la anterior regulación, caracterizada por un automatismo poco acorde con lo deseable en materia de valoración de riesgos. No obstante, no conviene ser excesivamente optimistas, en la medida en que el régimen establecido para la delincuencia sexual y el terrorismo no ha experimentado cambio alguno, obteniendo como resultado una regulación dual en función de la tipología delictiva o, mejor aún, de la específica reforma penal a la que esté asociada.

Y esta no es la única herencia que se puede deducir de la reforma de 2010, siendo así que el legislador de 2015 reproduce el «estilo» de la norma precedente cuando decide conectar la libertad vigilada a la categoría de homicidio y sus formas, sin discriminar entre los tipos (quedando subsumidos también el homicidio imprudente o la inducción al suicidio, por ejemplo) ${ }^{50}$. Técnica que ya generó múltiples reservas cuando se inauguró para los delitos de terrorismo y los delitos sexuales, dos categorías cuya amplitud y variedad quedan simplificadas en exceso cuando la asig-

49 Por ejemplo, reza el artículo 156 ter del Código Penal: «A los condenados por la comisión de uno o más delitos comprendidos en este Título, cuando la víctima fuere alguna de las personas a que se refiere el apartado 2 del artículo 173, se les podrá imponer además una medida de libertad vigilada.»

50 Salat Paisal (2016), p. 175.

(C) UNED. Revista de Derecho Penal y Criminología, 3. ${ }^{a}$ Época, $n .^{\circ} 20$ (2018) 
nación de la medida de libertad vigilada se asocia a un Capítulo o Título (respectivamente) al completo. Afortunadamente, en estas tres últimas incorporaciones los defectos resultan paliados al abrir la puerta al juzgador para decidir desde el primer momento cuándo resulta pertinente la imposición de la medida, posibilidad no contemplada bajo la ley 5/2010.

Cabe señalar también que, para las figuras introducidas en 2015, no será de aplicación el límite de hasta 10 años de libertad vigilada, quedando ésta restringida a un máximo de 5 (SALAT PAISAL, 2016, p. 164). Unir este detalle con los apuntes anteriores induce a pensar que el legislador tiende a considerar que, en esta segunda ocasión, se ha encargado de regular supuestos de menor seriedad (¿peligrosidad?) relativa, a la vista del régimen considerablemente más flexible e individualizador. Si se acepta tal interpretación, sin embargo, se evidencia la complicación de comparar uno a uno los tipos subsumidos bajo cada régimen, comparación que tiende a producir resultados paradójicos en términos de proporcionalidad $^{51}$. De estas paradojas y la información que puede extraerse de ellas nos ocuparemos en una sección posterior.

c) Observaciones y críticas. Necesidad, eficacia y eficiencia

La libertad vigilada se ha encontrado en una peculiar situación prácticamente desde sus inicios. Planteada inicialmente como pena, emergería finalmente como medida de seguridad y cargada de un contenido connotativo más claramente demarcado de lo que cabía esperar de su desconcertante literalidad. Así, pesa sobre la medida no sólo una técnica legislativa deficiente y de contornos imprecisos, sino también su lugar en el Código Penal como único exponente manifiesto de un proclamado viraje hacia el dualismo penal.

Resaltando nuevamente el énfasis en el control del condenado tras su liberación, parte de la doctrina llama la atención sobre el hecho de que se haya creído necesario instituir mecanismos de esta suerte conforme se ha ido dificultando la tarea para la que el sistema progresivo de tratamiento penitenciario había sido concebido (ACALE SÁNCHEZ, 2013, pp. 433-436; SALAT PAISAL, 2016, p. 170). La introducción de normas tendentes a asegurar el cumplimiento íntegro de las penas en el interior de los centros penitenciarios no sólo resulta sintomática de un clima general de carácter punitivo-inocuizador, sino que alumbra desde otro ángulo la necesidad de articular mecanismos de control postpenitenciarios. El anquilosamiento de la individualización penitenciaria a través

51 Así, por ejemplo, menciona SALAT PAISAL (2016, p. 176) la comparación entre los delitos contra la vida y pornografía infantil, mostrando que, aunque para el primer caso nunca superaríamos los 5 años de libertad vigilada, para el segundo podríamos llegar a adentrarnos en el tramo de los 5 a 10 años. 
de restricciones de carácter general, si bien es cierto que seguramente consigue los fines "preventivos» propuestos a corto plazo (a través de la segregación prolongada de la población penitenciaria respecto de la sociedad civil), lo hace al precio de consolidar el problema de la «liberación de presos no reintegrados» a nivel sistémico. Como consecuencia, y dado que la liberación ha de llegar tarde o temprano, emerge la necesidad de una extensión de la intervención del sistema penal a través de mecanismos de control que, paradójicamente, tienen como misión atajar problemas que han sido propiciados en buena medida por la dirección político criminal adoptada ${ }^{52}$.

Mas esto no es sino parte de la cuestión, y quizás no la más delicada. Considerando que la orientación que suele actuar como eje de propuestas como la libertad vigilada es básicamente utilitaria, los esfuerzos críticos seguramente no puedan desentenderse de esta faceta del debate. En concreto, y al margen de sus defectos, la libertad vigilada sería seguramente considerada apropiada por muchos siempre que fuera necesaria, eficaz y, con no menos importancia, eficiente. Desde luego, sería imposible hacer más que sobrevolar la cuestión en un texto de estas características, motivo por el cual nos limitaremos a ofrecer algunas pinceladas de aspectos clave sobre los que puede plantearse la discusión. Examinemos cada una de las facetas de este pragmatismo político criminal en orden.

\section{Necesidad}

La cuestión de la necesidad supone un punto de partida peculiar en cuanto que resulta raramente discutida de modo expreso: la identificación de un problema político criminal, cuya envergadura es presupuesta con relativa frecuencia, sirve como justificación para la intervención sobre el mismo, quedando la reflexión a menudo elidida en la vorágine de propuestas $^{53}$. Podría incluso plantearse si la necesidad no actúa en

52 En este contexto, los objetivos de tratamiento, reinserción, y los mecanismos progresivos de transición a la libertad quedan consolidados como «beneficios penitenciarios» (ACALE SÁNCHEZ, 2013, p. 435) destinados a los reos más inocuos y bien dispuestos mientras que, para el resto, se despliega una suerte de red de control y supresión que ha de durar tanto como sea posible. A ello contribuye la libertad vigilada, y aunque es cierto que en la práctica se abre alguna vía para el ejercicio de la discrecionalidad judicial en la no aplicación de la medida, se han alzado voces que se muestran considerablemente escépticas (MARTínEZ GARAY, 2014, p. 29) sobre la viabilidad de este mecanismo como forma de contener la expansión del control postpenitenciario a la gran mayoría de reos condenados por alguno de los delitos previstos.

53 De hecho, es esta misma omisión la que enfatiza la necesidad: cuanto más imperativo parece intervenir sobre un fenómeno a través de toda suerte de protocolos y mecanismos, tanto más paradójico parece plantearse si todo ello es realmente necesario. Visto de otro modo, la decisión de intervenir lleva consigo la atribución de la necesidad hacerlo, de tal manera que no permite (o cuando menos dificulta, hace parecer desfasado) el cues- 
ocasiones como un axioma político criminal que instruye los posicionamientos de los diversos autores en relación con la materia normativa de que se trate.

Sea como fuere, cabe preguntarse si el legislador ha sabido evaluar adecuadamente las necesidades experimentadas por la sociedad en materia de seguridad, a la vista de las tipologías delictivas escogidas, especialmente, en la primera iteración a través de la LO 5/2010. En particular, se ha contemplado con escepticismo la inclusión de los delitos de terrorismo a la vista de la ya desmedida penalidad que les es atribuida conforme se incrementa la gravedad, considerando que tras varios lustros (o incluso décadas) en prisión, resulta poco probable que exista un riesgo de reincidencia tal que requiera medidas como las propuestas durante plazos como los propuestos ${ }^{54}$. Algo similar se ha podido defender en relación con la delincuencia sexual, resaltando la escasa reincidencia que tiende a mostrar este subconjunto de penados con respecto al resto ${ }^{55}$. Y aunque se ha afirmado que esta medida podría haber sido concebida con cierto tipo de delincuentes altamente violentos y recalcitrantes en mente ${ }^{56}$, esto nos retrotrae de nuevo al interrogante de si son

tionamiento de esta (como plantearse si era necesario salir de casa por la mañana cuando uno ya se encuentra en trayecto). Por lo que a la discusión jurídico penal respecta, otro proceso interviene frecuentemente para desactivar la elección de la necesidad como tema protagonista: y es que los cambios legislativos sitúan el debate en un momento posterior en el que el uso más eficaz de las energías disponibles no pasa por examinar trabajosamente si las reformas cumplían con una estimación racional de las necesidades político criminales o dogmático penales, sino por producir criterios interpretativos adecuados capaces de sacar lo mejor posible de la normativa existente.

54 Martinez Garay (2014, p.18-19), citando el comentario de Llobet Anglí (2012, pp. 723 y ss.) para el contexto español y el terrorismo de ETA. Más generalmente, el concepto de «reincidencia terrorista» es concebido como altamente problemático a nivel definitorio y empírico, resultando poco claro que el grado de preocupación por la reincidencia de los condenados por este tipo de delitos venga respaldada por un fenómeno de reincidencia palpable (especialmente en el ámbito de las democracias occidentales). Ver HORGAN y BRADDOCK (2010), pp. 268-271.

$55 \mathrm{Y}$ aunque las cifras tienden a variar, parece existir cierto consenso en torno a la idea de que los delincuentes sexuales como categoría global presentan tasas de reincidencia significativamente menores a otras categorías delictivas, así como en comparación con la tasa global correspondiente a la población penitenciaria. Así, el estudio de HerRERo (2013) refleja una tasa de entre un 15 y un 20\%, mientras que los estudios efectuados en 2009 y 2014 en las prisiones catalanas muestran alrededor de un 19\% (Centre d'Estudis Jurídics i Formació Especialitzada, 2009, p. 120; 2015, p. 137)

56 Cabe destacar, en este sentido, las contradicciones que emergen cuando se legisla pensando en un tipo concreto de criminal, pero se actúa sobre categorías amplias y heterogéneas de autores criminológicamente alejados del tipo ideal. Ejemplo siempre interesante en este sentido supone la legislación en materia de delincuencia sexual, generalmente ideada para un prototipo de agresor sexual que no se corresponde con la inmensa mayoría de la casuística, en que la agresión o el abuso se desarrolla dentro del círculo cercano a la víctima (notablemente familiares y amigos). Véase: NAVARro Frías (2011), pp. 126-132; TORRES RosELl (2012), p. 35. 
estos los sujetos que plantean serios problemas político criminales en la actualidad y, si así fuera, en qué sentido ${ }^{57}$.

Con la reforma de 2015 la discusión se hace considerablemente más compleja con motivo de la introducción de los casos de violencia doméstica y de género, que parecen apuntar en una dirección político criminal totalmente distinta al resto. Las características de este tipo de criminalidad, tanto por su prevalencia como por su naturaleza insidiosa y vinculada a elementos culturales recalcitrantes aún por superar, la sitúan prácticamente en oposición a la mayoría del resto de figuras contempladas por la libertad vigilada (fundamentalmente excepcionales, tanto por su gravedad como por su escasez). Esta disparidad apunta ya, de manera clara, a que lo más apropiado sería plantearse si la regulación establecida era necesaria, no sólo globalmente, sino para cada uno de los casos contemplados por ella.

Finalmente, y al hilo de la reflexión iniciada más arriba, permanece la duda de si la necesidad que pudiera atribuirse a la libertad vigilada en nuestro sistema jurídico se derivaba, no tanto de cuestiones criminológicas o de política criminal en sentido estricto, sino por los cambios en política penitenciaria cuyas eventuales contradicciones la nueva medida viene a tratar de paliar. Si así fuera, nuestra única medida de seguridad orientada al delincuente imputable peligroso vendría viciada en su núcleo mismo en tanto que cumpliría la misión de trasladar a determinados sujetos la carga de un problema sistémico provocado por una política penal rigorista. Si entendemos como correlativas la excepcionalización de los mecanismos penitenciarios orientados a la reinserción y la extensión de la intervención inocuizadora a través de la libertad vigilada, nos podríamos ver obligados a aceptar que esta "función homeostática» supone una instrumentalización de los penados más repudiados para la subsistencia de un edificio penal sobredimensionado. Y esto fundamentalmente a través de una redistribución de las cargas derivadas del progresivo abandono de toda finalidad más allá de la segregación penitenciaria, estrategia que, a largo plazo, propicia unos riesgos en el momento de la puesta en libertad que pasan a actuar como justificación de ulteriores medidas de seguridad. La armonización de dicha instrumentalización con el respeto a la dignidad de la

57 Quizás procede incluso complejizar la idea de «problema político criminal», indagando sobre qué tipo de problemas político criminales produce este tipo de delincuencia y sobre quién repercuten fundamentalmente. Así, frente a la representación habitual del criminal peligroso como una amenaza para la sociedad emerge la incógnita del peso específico de este tipo de riesgos frente a otros, así como su capacidad o no para producir una lesión de entidad suficiente a escala social (dado que en este nivel es donde se sitúa la amenaza habitualmente). No menos pertinente es la percepción del «problema político criminal» como un "problema para la política criminal», especialmente en la medida en que la mediatización de este tipo de casos parece amenazar tácitamente con poner en entredicho la legitimidad de las instituciones y de la Justicia estatal. 
persona parece, en este sentido, un escollo nada desdeñable dentro de parámetros democráticos.

\section{Eficacia}

Intensamente conectado con lo anterior está el problema de la eficacia. La pregunta fundamental aquí reside en si la medida de libertad vigilada puede producir los efectos para los que en principio ha sido articulada, lo cual ya es un problema a la vista del contenido heterogéneo de la medida. En cualquier caso, en términos generales parece claro que se busca prevenir la peligrosidad atribuida a los sujetos que alcanzan la liberación sin haber sido "rehabilitados», tal y como manifiesta el legislador. Adicionalmente, hemos visto que este objetivo se pretende satisfacer fundamentalmente a través de mecanismos de control antes que correctivos/tratamentales. Aquí surge una primera duda en cuanto a la eficacia que quepa esperar de la medida, no sólo durante su ejecución, sino en el periodo posterior a la supervisión. Además, incluso asumiendo la óptica del control, resulta razonable preguntarse si, ante individuos "no rehabilitados», las medidas instauradas son capaces realmente de prevenir la comisión de nuevos delitos (NAVARRO FRÍAS, p. 158) ${ }^{58}$ a la vista de que su eficacia preventiva actúa, cuando más, de manera indirecta antes que como inocuización en sentido fuerte. Una alternativa pasaría por entender que se trata de mecanismos más útiles a la hora de asegurar una mayor facilidad en la reabsorción del sujeto por el sistema penitenciario (facilitando la detección de nuevos delitos, la prueba de los mismos, así como la cristalización de infracciones como quebrantamientos de condena $)^{59}$. Finalmente, se ha sugerido que este tipo de expansión de la atadura penal puede llegar a resultar contraproducente o, incluso, directamente criminógena (VÁZQUEZ GONZÁLEZ, 2013, p. 264).

El último punto, pero no menos significativo en términos de eficacia, es el que deriva de la falta de concreción en relación con la forma en que ha de ejecutarse la medida de libertad vigilada, así como sobre la dotación de medios materiales y personales oportunos a tal efecto. $\mathrm{Y}$ es que, del examen del Derecho comparado en la materia, se deduce rápidamente que los ordenamientos con los mecanismos de supervisión postpenitenciaria más acabados han estructurado la correspondiente

58 Considérese también, en materia de delincuencia sexual particularmente, la inadecuación de los medios arbitrados por la libertad vigilada en relación con algunos tipos concretos de delitos, como los que se efectúan en el seno del hogar familiar o, de forma aún más llamativa, aquellos que se cometen a través de Internet. Véase: RAMos VÁzQUEZ (2012), pp. 218 y ss.

59 Algo que Lin, Grattet y Petersilia (2010) denominan «back-end sentencing» haciendo referencia a los reingresos penitenciarios que se producen por incumplimientos de condiciones de liberación no necesariamente vinculadas a la comisión de nuevos delitos. 
red de profesionales encargados del seguimiento de los sujetos sometidos a supervisión. Instituciones como la probation estadounidense o la vigilancia de conducta alemana implican un despliegue más que considerable de medios, planificación y fondos sobre los cuales nuestro legislador ha decidido guardar silencio. La inexistencia, ampliamente denunciada $^{60}$, de una figura como el agente de libertad vigilada plasma el retrato de una «libertad vigilada sin vigilante» (MARTÍNEZ GARAY, 2014, p. 23) o, quizás, una idea no asistencial de supervisión de penados, en línea con ciertas tendencias político criminales (NELLIS, 2014, pp. 503-505).

\section{Eficiencia}

Discutir sobre la eficiencia de las medidas de supervisión en libertad se ha hecho prácticamente imperativo por múltiples motivos. Por un lado, esta forma de concebir la penalidad en libertad ha venido prácticamente desde sus inicios respaldada por una suerte de lógica economicista que parece armonizar bien con las inclinaciones neoliberales que han venido caracterizando de forma variable las políticas (económicas principalmente) de los Estados a lo largo de las últimas décadas ${ }^{61}$. De acuerdo con este razonamiento, la supervisión en libertad sería una forma mucho más eficiente de penalidad en tanto que permitiría el control de los sujetos sin necesidad de asumir su onerosa manutención y permitiendo, además, que este siga funcionando en sociedad como agente económico (y como contribuyente). Esto vendría complementado por la creciente informatización de los sistemas técnicos de supervisión, sustituyendo la necesidad de una ingente cantidad de personal más o menos cualificado por un sistema automático de registro de la actividad del condenado capaz de generar alertas cuando alguno de los criterios preestablecidos en el programa es vulnerado. El sueño del panoptismo de BENTHAM habría encontrado en los dispositivos de geolocalización su forma perfecta (MURPHY, 2008, p. 1385; TORRES ROSELL, 2012, p. 28), una en la que cada cual lleva consigo a la prisión y al vigilante, transformando el encierro en una condición subjetiva, una aprehensión directa del Estado sobre la conciencia del individuo.

Sin embargo, rara vez la realidad cristaliza conforme a los sueños y deseos de los visionarios, y la práctica de la supervisión en sus distintas formas ha tendido a arrojar una imagen compleja de la eficiencia previsible de este tipo de medidas. Buena parte de las ventajas esperadas en materia de reducción de costes viene asociada a la implementación de

60 Entre otros: Manzanares SAmaniego (2010); Martínez Garay (2014); Otero GonZÁLEZ (2015); SALAT PAisAl (2015).

61 Brandariz García (2014), pp. 16-17. Conectando neoliberalismo con el seguimiento electrónico de penados NelLIS (2014), p. 504.

(C) UNED. Revista de Derecho Penal y Criminología, 3. ${ }^{a}$ Época, $n .^{\circ} 20$ (2018) 
medios tecnológicos de vigilancia y supervisión, cuyos alicientes en este sentido parecen difíciles de obviar ${ }^{62}$. Así, a pesar de los costes iniciales de implantación y de mantenimiento de los dispositivos, normalmente suele argüirse que todo ello sigue resultando más rentable que el internamiento, habida cuenta, además, de la tendencia al abaratamiento que produce el avance tecnológico ${ }^{63}$. A ello se añaden las posibilidades en materia de privatización de costes y gestión que han caracterizado la implementación de este tipo de medidas en otros países ${ }^{64}$.

Ello no obstante, la instauración de este tipo de supervisión, especialmente cuando viene apoyada por medios electrónicos, puede trasladar los costes a otra parte de la puesta en práctica. La literatura, en este sentido, tiende a subrayar la multiplicación de labores de comprobación (ARMSTRONG y FREEMAN, 2011, p. 180; PAYNE y DEMICHELE, 2010, p. 280) que pueden requerir (según el tipo de control implementado) desplazamientos habituales del personal de supervisión hacia el emplazamiento de los distintos sujetos sometidos a vigilancia, con la complicación ocasionada por su dispersión geográfica. Esto parece venir drásticamente agravado habida cuenta de la frecuencia con que los dispositivos de seguimiento pueden desencadenar alertas por una gran variedad de motivos distintos del quebrantamiento de las reglas impuestas (frecuentemente por cuestiones técnicas como pérdida de señal, descarga de la batería...) (ARMSTRONG y FREEMAN, 2011, p. 180)

Y desde luego, lo anterior no entra ni siquiera a considerar los costes asociados a la instauración de un modelo de supervisión en libertad que tratase de emular los modelos más consumados que arroja el ámbito comparado. En tal caso, habría que considerar el impacto presupuestario nada desdeñable de crear un cuerpo profesional adecuadamente formado, financiado, distribuido como mínimo a nivel provincial, y orientado a desarrollar labores individualizadas de asistencia con el fin de facilitar y consolidar la reinserción social de los sujetos que han cumplido su pena de prisión.

62 Uno de los cálculos más llamativos que han sido presentados sobre el particular ha sido que por cada individuo encarcelado podrían ser sometidas a vigilancia electrónica en torno a seis personas (MuRPHY, 2008, p. 1370), no obstante, estudios piloto desarrollados en los últimos años han arrojado una imagen más variada del beneficio económico esperable (NELLIS, 2014, pp. 492-499).

63 Procede recordar que la medida de libertad vigilada, a pesar de su nombre, no tiene por qué cristalizar en el seguimiento mediante dispositivos electrónicos, lo que apunta ya a un coste diferencial en la imposición de unas reglas u otras en la determinación del contenido concreto de la medida. Por ello surgen dudas razonables sobre si, a falta de criterios o directrices claras sobre el tipo y cantidad de reglas a imponer, no pudieran acabar favoreciéndose las opciones menos onerosas.

64 Llegando a establecerse en ocasiones que los propios sujetos supervisados tuvieran que soportar al menos parte de los costes aparejados a la implantación de dispositivos electrónicos (MURPHY, 2008, p. 1371). 
Mas existe un último punto cuyo peso rinde prácticamente irrelevante la mayoría de las consideraciones anteriores. Y es que, si atendemos a la forma en que ha sido articulada la medida de libertad vigilada en nuestro sistema, su consideración como medida acumulativa a la pena de prisión, desvinculada de cualquier reducción del periodo de internamiento penitenciario, hace poco viable cualquier aspiración a economizar fondos para las arcas públicas. Este es un dato importante, pues reduce nuestras opciones interpretativas: o el legislador ha optado por asumir los costes derivados de la implantación de un sistema que considera necesario (quizás precisamente a sabiendas de que este se orienta a una parcela relativamente pequeña de la población penitenciaria), o acaso se ha decantado por introducir un nuevo ejemplo de legislación simbólica siguiendo la estela de otras reformas anteriores que quedan desarmadas en la práctica por ausencia de medios (MARTÍNEZ GARAY, 2014, p. 49). Sea como fuere, lo eficiente que pudiera ser la libertad vigilada en ejercicio parece ser el último de los problemas.

d) Sobre los límites de la libertad vigilada

Finalmente, algo merece ser dicho sobre el potencial que alberga la medida de libertad vigilada. No es infrecuente observar una tendencia a considerar las medidas que se desarrollan en libertad como un «mal menor» a la vista de la alternativa: seguir haciendo lo mismo de siempre a través de la extensión del internamiento ${ }^{65}$. Esto viene acrecentado, a buen seguro, por la relativa inocuidad con que aparece cada regla de conducta que puede imponérsele al sujeto en libertad, especialmente consideradas individualmente. ¿Qué mal puede hacer la obligación de presentarse periódicamente ante el juez, si la alternativa ${ }^{66}$ es el confinamiento en una celda reducida de la cárcel correspondiente?

Sin embargo, un análisis del alcance de la libertad vigilada demanda un examen más detallado. Por un lado, la distinta naturaleza e intrusividad de cada una de las reglas de conducta requeriría cierta jerarquización o, como mínimo, una vinculación con las específicas necesidades del caso concreto. Especialmente imperativo parece el delinear algún

65 Véase que, a pesar de expandir notablemente el alcance de la libertad vigilada, el grueso de la atención recabada por el Anteproyecto de 2012 aterrizaría sobre las expresiones de internamiento, cuyo potencial restrictivo hacía palidecer en comparación al collage de reglas de la libertad vigilada.

66 Recuérdese que la regla general de la libertad vigilada en nuestro ordenamiento no es, sin embargo, la de la alternatividad, sino la de la acumulación, de tal manera que supone la adición de un mal, no la sustitución de un régimen de restricción por otro menos gravoso. En todo caso, la alternativa hipotética se da si uno considera que, de no haberse introducido la medida de libertad vigilada, habría sido necesario ampliar nuevamente los marcos penales de algunos delitos. 
tipo de criterio frente a la aplicación acumulativa ${ }^{67}$ de las distintas reglas de conducta de forma a evitar transformar el cumplimiento de la medida de seguridad en un auténtico "destierro» en el seno mismo de la sociedad a la que se regresa pero que no se reintegra.

En este sentido, seguramente sea acertada la idea de MURPHY de que resulta necesario desprenderse, al menos en parte, de la prisión como «paradigma de contención» a la hora de reflexionar sobre las crecientes formas de control en la comunidad. Las cualidades lesivas, degradantes y desocializadoras de la reclusión son a estas alturas bien conocidas, sin embargo, la vigilancia en libertad es susceptible de adoptar (y ya adopta en el ámbito comparado) formas que manifiestan una capacidad para producir perjuicios, estigma y segregación de una manera que le es propia, específica, y cuyo análisis apropiado puede venir enturbiado por el recurso a la comparación con la pena de prisión (MURPHY, 2008; pp. 1349-1351 y 1364-1365). Del mismo modo que se ha defendido que la cárcel era capaz de resocializar dadas las circunstancias apropiadas, seguramente también sea posible entender que las medidas de supervisión en la comunidad pueden favorecer la reintegración adecuada de los sujetos sometidos a ellas ${ }^{68}$. Ahora bien, la cuestión crucial siempre ha sido el cómo, de qué manera dotamos a los mecanismos que empleamos de la capacidad efectiva de promocionar un regreso sostenible a la vida en libertad con respeto de la legalidad.

Asumir que la libertad vigilada, como medida de supervisión en libertad, resulta automáticamente menos lesiva que cualquier medida de internamiento supone una simplificación ${ }^{69}$ que, sin ofrecer grandes pistas analíticas, puede entorpecer la tarea de determinar bajo qué condiciones habría de desenvolverse para poder considerarse como sustancialmente mejor como paradigma de penalidad. Lamentablemente, estos esfuerzos se enfrentan de entrada al obstáculo derivado de la lógica punitivista, que ha instituido en nuestro ordenamiento esta medida como meca-

67 A título de mero ejemplo, una acumulación que puede producirse con relativa facilidad es la de imponer el seguimiento mediante medios electrónicos con la prohibición de acudir a determinados lugares, si bien nada parece impedir la mera adición indefinida de otras condiciones. Habida cuenta de las limitaciones que la vida ordinaria en libertad impone en materia de elección de dónde se reside, por qué lugares se pasa, durante qué horarios, etc... la reflexión sobre el potencial de constricción de las medidas de este tipo resulta indispensable si realmente se pretende dotarlas de un mínimo de eficacia.

68 Si bien comenta TorRes Rosell (2012, pp. 30-31) que probablemente los efectos a obtener en este sentido vengan vinculados a su aplicación conjunta con medidas tratamentales. Una sinergia que destaca significativamente dentro del clima oposicional que tiende a caracterizar el debate entre posiciones asegurativas y rehabilitadoras.

69 Citando a Murphy (2008): "Many people may prefer a year under electronic monitoring to a year in jail (...). Rephrase the question as a choice between one day of incarceration and a year of intensive technological surveillance, however, and choosing the least offensive option may appear more complicated. Many people would likely trade a year in jail to avoid a lifetime ban from their hometown or the indelible stigma of public registration»(p. 1372). 
nismo para extender la vigencia del control penal más allá del periodo penitenciario, contribuyendo a la optimización de la política criminal inocuizadora para la que todo riesgo posible es un riesgo inasumible.

\section{Reconstruyendo la imagen legal del delincuente imputable peligroso}

\section{Consideraciones generales}

Como hemos podido examinar a lo largo de las líneas precedentes, el viraje dualista asumido por nuestro ordenamiento jurídico ha sido generalmente de carácter modesto a la vista de lo que hubiera podido ser. Su cristalización a través de una única medida, de espectro limitado a pesar de las ampliaciones efectuadas, permite ver la transición iniciada en 2010 como un "subprograma» dentro del sistema jurídico penal, una especialidad dirigida hacia un colectivo específico que ha recibido en el proceso la etiqueta del «delincuente imputable peligroso».

La pertenencia a esta resucitada categoría penal (que aquí hemos definido esencialmente como los receptores potenciales de una medida de libertad vigilada) tiene, sin embargo, unas implicaciones nada desdeñables en tanto que abre la puerta a un Derecho penal caracterizado por la sospecha y la precaución cuyas manifestaciones son concretas: para los sujetos considerados peligrosos el cumplimiento de la pena no supone saldar cuentas con la sociedad, sino que legitima al Estado a extender su supervisión a la vida en libertad, de la manera que se estime conveniente y dentro de unos límites inciertos. El planteamiento subyacente es claro: la reiteración delictiva llevada a cabo por estos sujetos tras su puesta en libertad se ha vuelto un riesgo inaceptable, una carga que ya no resulta legítimo hacer soportar a la sociedad sin una barrera paliativa adicional. La libertad vigilada trata de ser esa barrera, si bien mucho queda aún en duda sobre las posibilidades que tenga de serlo.

Sobre estos sujetos «especiales» nos volcamos pues, a modo de síntesis y cierre. Los delincuentes imputables peligrosos legalmente determinados son una figura un tanto paradójica desde un entendimiento clásico: plenamente responsables de sus actos pero objeto de una prevención semejante a los individuos inimputables. Su peligrosidad, se entiende, no queda inscrita claramente dentro de los cánones de la patología ${ }^{70}$ sino que nos obliga a recurrir a vías de racionalización menos claras, como la «radicalidad», la «inclinación delictiva», la «desviación sexual» y otras

70 Sirva de ejemplo el uso de la expresión «trastorno de personalidad o de conducta» que empleaba el prelegislador en la tan reveladora Exposición de Motivos del Proyecto de 2009, elección que no puede ser casual en tanto que nos habla simultáneamente de un rasgo diferencial del individuo y de su plena imputabilidad. 
expresiones de una suerte de corrupción moral subyacente, que instruyen la necesidad de articular mecanismos asegurativos específicos. El empleo de esta clase de conceptos permite caracterizar al sujeto a la vez como suficientemente diferente del resto de la población como para ser definido en términos de amenaza para la misma, pero sin llegar a implicar un grado de diferencia tal como para desactivar la respuesta penal a través de una disminución de la imputabilidad ${ }^{71}$.

Como hemos visto, nuestro legislador distribuye este tipo de casos en cuatro grandes categorías: autores responsables por delitos de terrorismo, delincuencia sexual, delitos contra la vida y violencia doméstica o de género. De manera un tanto intuitiva, resulta tentador entender que el nexo común radica en que se trata de tipos de delincuencia violenta especialmente grave. Mas ha quedado claro que esto tan sólo es asumible cuando tenemos en cuenta las categorías generales y que, de hecho, en tal caso estaríamos cometiendo el mismo error que, potencialmente, ha cometido el legislador: atribuir a cada «familia típica» las características que suelen asociarse (justificadamente o no) a los tipos más graves. Así, igual que la delincuencia sexual queda cortada al patrón del «sexual violent predator ${ }^{72}$ y similares, el resto de conjuntos experimentan análogo tratamiento, quedando reducida toda su diversidad en un ejercicio de estereotipia legislativa. Este es el criterio de peligrosidad «categorial» que hemos podido examinar al inicio del texto y sobre el cual no conviene extenderse más de lo que ya se ha podido hacer anteriormente.

Una consecuencia llamativa de esta forma de delimitar a grandes rasgos los supuestos en que resulta posible intervenir sobre la base de la peligrosidad reside en la inevitable comparación entre tipos dentro y fuera de sus propias familias. Los problemas de comparación «intrafamiliar» derivan del uso de amplias categorías de peligrosidad vinculadas a capítulos o títulos enteros del Código, como se ha podido ver. Los problemas «interfamiliares», a su vez, añaden la dificultad derivada de la respuesta dual que el legislador ha acabado plasmando al atribuir distinto régimen jurídico a los tipos incorporados en 2010 y en 2015, produciendo en el proceso singulares paradojas. Sobre estas dificultades y aparentes contradicciones podemos, sin embargo, tratar de apoyarnos para remontar hacia el concepto de peligrosidad empleado por el legislador en tanto que, justificadas o no, resultan constitutivas de la efectiva plasmación penal de la delincuencia peligrosa.

71 En el proceso, parece delinearse una forma de otredad social que resulta tanto más amenazante en cuanto que no es capaz de suscitar el tipo de compasión aparejada a la enfermedad mental. Siendo sus transgresiones fruto de una «anormalidad no patológica», queda abonado el camino para recurrir a explicaciones afines a la perversión y otras formas culturales de maldad. Ver, por ejemplo, DouARD (2008), pp. 48-49.

72 Algo que se ha denunciado con cierta frecuencia en el contexto estadounidense (Douard, 2008, pp. 35 y ss.). Ver también Ramos VÁzouez (2012, pp. 192-201); Robles Planas (2007). 


\section{Reflexiones preliminares. Componentes de la peligrosidad}

Con la intención de remontar hacia el concepto de peligrosidad criminal empleado por el legislador se pretende partir de los tres interrogantes identificados más arriba: el problema de la selección de las categorías de peligrosidad, el problema de comparación «interfamilias», y el problema de comparación entre tipos pertenecientes a una misma familia.

El primer caso implica reflexionar sobre cuál ha podido ser el criterio de inclusión/exclusión empleado por el legislador para escoger qué categorías quedarían subsumidas dentro de la libertad vigilada. Esto supone, en el fondo, plantearnos por qué esos delitos específicos y no otros. El segundo de los puntos nace de la disparidad de régimen dispensado a las categorías, especialmente considerando que las introducidas por la reforma efectuada en 2010 (terrorismo y delincuencia sexual) son objeto de un tratamiento más constrictivo en la ley que aquellas inauguradas con la reforma de 2015. Por último, a nivel «intrafamiliar», habremos de ahondar en una cuestión que tiene dos facetas: por qué tipos distintos reciben en principio el mismo tratamiento y de qué manera, en su caso, se ha pretendido moderar tal automatismo.

Para tratar de abordar sucesivamente estos tres frentes se debe examinar, como paso previo, el concepto de peligrosidad criminal para tratar de desmenuzarlo en sus componentes elementales. Asumiendo la más escueta de todas las concepciones, cuando se habla en términos de peligro se pretende hacer referencia a la probabilidad de que ocurra en el futuro un suceso considerado como dañoso ${ }^{73}$. Probabilidad y daño son aquí términos clave, pues de su combinación deriva buena parte del significado de la noción. Adicionalmente, ambos deben ostentar un mínimo de entidad, de tal manera que ni el acontecimiento que se anticipa puede ser irrelevante o inocuo si ha de ser leído en términos de amenaza (peligro), ni la probabilidad puede ser tan escasa como para ser considerada insignificante.

Avanzando un paso más en la reflexión, y conectándola ya con el ámbito jurídico penal, procede efectuar unas precisiones. En primer lu-

73 A pesar de esta concepción general, nuestro Código penal permite un grado adicional de anticipación, en la medida en que resulta posible desprenderse de la referencia directa al daño para pasar a una indirecta. Véase la regulación para el online child grooming (183 ter CP). Esta figura delictiva no tiene su anclaje típico en la producción de un daño concreto (un abuso sexual, por ejemplo), sino en la realización de conductas que se entienden orientadas a tal fin o, si nos centramos en el apartado segundo, ni siquiera. La imposición de una medida de libertad vigilada a un «delincuente peligroso» condenado bajo esta figura supone, en consecuencia, redefinir la peligrosidad como el riesgo, no de producir un daño, sino de emprender conductas que pueden (o no) derivar ulteriormente en un daño. En otros términos, un intento de aprehender la "peligrosidad de la peligrosidad». 
gar, tanto el legislador como los operadores jurídicos se ven obligados, al valorar la peligrosidad, a generar una expectativa sobre la posibilidad de que el sujeto pueda producir, con su conducta futura, alguna de las consecuencias que son consideradas dañosas. Esta expectativa no tiene más remedio que construirse con base en elementos presentes o pasados, que se emplean como reveladores o indicadores de lo que está por venir, como sucede en cualquier tipo de juicio prospectivo. De esta manera, la gravedad del hecho futuro viene, las más de las veces, inferida del hecho pasado que, en nuestro caso, es el delito cometido ${ }^{74}$.

Esto es especialmente relevante cuando el concepto de peligrosidad adopta la forma que le ha otorgado nuestro legislador. Y es que, cuando este dirige su atención hacia determinados colectivos «peligrosos» que ha clasificado esencialmente por el tipo de delito cometido, ¿le preocupa prevenir todo delito futuro en que puedan incurrir? Si así fuera, ¿por qué seleccionar a un subgrupo tan (relativamente) específico si luego va a tratar de obtener de ellos resultados totalmente inespecíficos? Más bien parece que, si ha de existir una relación funcional entre la selección efectuada y los objetivos preventivos (una adecuación entre medios y fines, en cierto modo), esta se produce de manera que la delincuencia previa actúa como modelo de la delincuencia futura que se trata de prevenir. Esto quiere decir que, aunque la libertad vigilada sea susceptible de inhibir la reiteración delictiva en general, aquello que el legislador trata de evitar principalmente es la reincidencia específica ${ }^{75}$, a saber, la nueva comisión de un delito de similar naturaleza al que motivara la imposición de la medida de seguridad. Si esta interpretación resulta acertada, cabe deducir como consecuencia una nueva propiedad del delincuente imputable peligroso que puebla la mente del legislador: la del delincuente especialista, inclinado a repetir el tipo de conductas que conforman su clase específica de "desviación». Esto resultaría coherente con la representación del delincuente sexual como trastornado, y del terrorista como enemigo ideológico que la Exposición de Motivos del Proyecto de 2009 dejaba entrever, y no parece que venga contradicho por los tipos incorporados en 2015 (fácilmente reconducibles a categorías como «el asesino» o «el maltratador»). En todos los casos imágenes estereotipadas definidas por la clase de delitos que se les atribuye.

Hecha esta observación, podemos considerar que los criterios que componen el juicio de peligrosidad en nuestro ámbito son: un elemento

74 Aunque este no es el único indicador «fáctico» que hubiera podido emplearse, habiéndose resaltado por parte de la doctrina la ausencia de consideración de la reincidencia como criterio de peligrosidad ( $v$.gr. SANZ-Díez DE UlzurRun Lluch, 2013, p. 140). No obstante, parece que ésta haya acabado por asociarse más a las nociones de «habitualidad» que a la peligrosidad en el sentido que se desprende de la plasmación de la libertad vigilada.

${ }_{75} \mathrm{O}$ reincidencia en sentido propio, si se quiere. 
fáctico, el delito cometido, que es medido generalmente en base a su gravedad; un acontecimiento futuro que, de acuerdo con el razonamiento anterior, será de una naturaleza al menos similar al delito ya cometido; y una estimación, cualitativa o cuantitativa, de la probabilidad de que tal acontecimiento se produzca. Estos dos últimos elementos pueden ser, en el contexto de este estudio, condensados de tal manera que nos quedemos finalmente con dos componentes: el hecho cometido, y la probabilidad específica de reincidencia ${ }^{76}$.

El subsiguiente análisis pretende emplear ambos componentes para ahondar en los tres "problemas» que señalábamos al principio, asumiendo que, si el legislador construyó su concepto de peligrosidad criminal conforme a una mínima reflexión sobre lo que significa la identificación de un peligro, habrá tenido que valorar expresa o tácitamente tanto el hecho cometido como una estimación de la probabilidad de que vuelvan a repetirse actos similares por el mismo autor.

\section{Releyendo al legislador: examen de las contradicciones}

Procederemos a examinar, por tanto, con algo más de detalle las tres contradicciones a la luz de ambos criterios, tratando de contemplar tanto las implicaciones interpretativas del sistema de facto implantado, como lo que éstas nos indican sobre la racionalidad legislativa empleada.

a) El problema de la inclusión/exclusión

El primero de los interrogantes que suscita la regulación establecida por el legislador con la libertad vigilada es uno de pertenencia/no pertenencia. Concretamente, averiguar qué criterio se ha empleado para discernir qué categorías debían quedar abarcadas (y cuáles excluidas) por la medida. Como hemos tenido ocasión de adelantar, la cuestión es poco clara y ha causado algún desconcierto en la doctrina.

Comencemos considerando únicamente la gravedad del hecho cometido. Partir de la aceptación acrítica de la labor del legislador aceptándola en sus términos nos obligaría a entender que, si éste ha sido el criterio empleado, las figuras delictivas bajo el paraguas de la libertad vigilada se corresponden con la criminalidad más grave. Esto, desde luego, resulta insuficiente tanto si consideramos las categorías genéricas como, especialmente, si entramos a valorar los tipos en ellas incluidas. Ni puede decirse que todos los casos se encuentren en un

${ }^{76}$ Entendida como probabilidad de comisión de un delito de naturaleza semejante al inicial.

(C) UNED. Revista de Derecho Penal y Criminología, 3. ${ }^{a}$ Época, $n .^{\circ} 20$ (2018) 
mismo rango de gravedad ni, para lo que ahora nos ocupa, que sean en todo caso más graves que otros tipos o familias delictivas que, sin embargo, no han encontrado reflejo en la regulación ${ }^{77}$. En consecuencia, el criterio de gravedad no funciona de manera autónoma como criterio de inclusión/exclusión dentro de la categoría de peligrosos (pues no consigue dar cuenta por sí mismo de la separación entre peligrosos y no peligrosos). Lo contrario hubiera sido sorprendente, pues hubiera implicado una atribución de peligrosidad en función de la culpabilidad, empleando la una como pasarela para la otra y desdibujando considerablemente sus límites.

Respecto de la probabilidad de reincidencia la cuestión se vuelve más compleja. Si asumimos que esta ha podido servir como criterio de inclusión/exclusión independiente, querría decir que el legislador considera que las cuatro categorías incorporadas ostentan un riesgo de reincidencia mayor que el resto de delitos no incluidos. Hasta cierto punto podría considerarse que ello es consistente con la necesidad declarada de instituir mecanismos para prevenir la peligrosidad en libertad de estos individuos "no rehabilitados». Incluso podría defenderse que, cuando la Exposición de Motivos del Proyecto de 2009 hablaba de «inclinación delictiva» confesaba a su vez sus expectativas sobre las posibilidades de reintegración de estos sujetos. No obstante, la cuestión es si este ha podido ser el criterio empleado por el legislador de manera exclusiva, lo cual resulta dudoso. Sin contar con las objeciones que podrían efectuarse al caso por caso ${ }^{78}$, obsérvese que el legislador no ha mostrado el más mínimo interés por orientar su acción a la delincuencia patrimonial cuyo protagonismo en las estadísticas de reincidencia es frecuentemente destacado ${ }^{79}$. Si el objetivo era controlar a los «clientes habituales» del sistema de justicia y prisiones, es seguramente por este colectivo por el que había que empezar.

Se abre ante nosotros, entonces, la necesidad de examinar si un juicio ponderado entre gravedad y probabilidad puede resultar más constructivo. Volviendo sobre el problema planteado por la delincuen-

77 Piénsese, por ejemplo, en los tipos más severamente castigados de tráfico de drogas, secuestros o incluso rebelión, cuyas penas pueden llegar ensombrecer a las contempladas para ciertos delitos incorporados bajo el paraguas de la libertad vigilada.

78 Entre las cuales, la menor reincidencia de los delincuentes sexuales frente a la media empieza a ser bien conocida, vid. supra, nota 54. Y aunque la investigación disponible tiende a evidenciar la necesidad de discriminar dentro del colectivo de delincuentes sexuales entre una mayoría relativamente inocua y una minoría de individuos recalcitrantes y problemáticos, los datos disponibles para nuestro país son todavía poco claros y contradictorios (NAVARRo Frías, 2011).

79 V.gr. Centre d'Estudis Jurídics i Formació Especialitzada (2015), pp. 136-137. Incluso en el APRCP 2012 el único acercamiento efectuado por el legislador a esta clase de delitos venía acompañado por la condición de que se hubiesen cometido con violencia o intimidación, dando a entender que es precisamente el actuar violento o agresivo el que determina la atención recibida en términos de peligrosidad. 
cia patrimonial, la escasa gravedad que le es atribuida habitualmente ${ }^{80}$ permite explicar que no se le haya otorgado una posición entre los peligrosos. Su recurrencia ante el sistema de justicia no parece hacerlos más amenazantes, lo cual nos permite ver que una alta probabilidad de reincidencia no es suficiente por sí sola para contrapesar una apariencia de inocuidad. Dándole la vuelta al argumento, sin embargo, sí podemos encontrar casos en que la gravedad consigue sobreponerse a la escasa probabilidad: piénsese nuevamente en la tasa de reincidencia de los delitos sexuales, o en la reincidencia de los terroristas. Esto nos conduce a determinar que un juicio combinado resulta más satisfactorio en cuanto a la selección de las componentes de peligrosidad (en la medida en que amplía nuestras posibilidades interpretativas), pero el valor relativo de ambas tenderá a ser asimétrico, concediendo cierta primacía a la gravedad.

Con todo, esta mejoría se muestra insuficiente y el punto flaco del razonamiento aparece desde dos frentes: por un lado, a través de las figuras graves de las que se puede deducir un riesgo importante de reincidencia (o, al menos, tan importante como muchas de las ya incorporadas) y que no han sido incluidas. Los delitos de tráfico de drogas en sus formas más cualificadas representan un claro ejemplo en la medida en que reciben penas más que severas y, al mismo tiempo, no incitan al entusiasmo en cuanto a la desistencia delictiva ${ }^{81}$. Por otro lado, las figuras de malos tratos habituales y lesiones dentro del ámbito doméstico y conyugal, sin dejar de ser graves, suponen un alejamiento significativo de la pauta marcada por las demás categorías, evidenciando mucho más intensamente que el motivo por el que han sido incluidas frente a otras formas delictivas con similar tratamiento penal no puede residir en una mera ponderación entre gravedad de la pena y probabilidad de reincidencia. Se intuye ya, pues, la presencia de otras variables no contempladas de carácter extrajurídico que intervienen seguramente como orientación para la producción legislativa de manera nada desdeñable.

80 Situación que se ha vinculado, entre otras posibilidades, a una multitud de factores vinculados al proceso de modernización: la sobreabundancia y fácil sustitución de la mayoría de bienes materiales por efecto de la consolidación de una economía de consumo, así como la institucionalización de los seguros como mecanismo paliativo frente a los riesgos patrimoniales de mayor trascendencia, entre otros, han contribuido a degradar al grueso de este tipo de criminalidad al rango de «bagatela» (o, al menos, a aliviar enormemente sus consecuencias). Ver PRATT (1997), pp. 103-112.

81 Ciertamente se podría defender que el conjunto de los condenados por tráfico de drogas no se corresponde con la imagen del «traficante» objeto de las más severas sanciones penales. Pero no es menos cierto que este criterio también era aplicable a los delitos sexuales que, sin embargo, fueron incluidos sin casi matices dentro de la libertad vigilada. A la luz del criterio seguido por el legislador, no hubiera sido extraño que la libertad vigilada se extendiera a los delitos vinculados con las drogas, habida cuenta del tipo de respuesta que han venido recibiendo tradicionalmente (CANCIO MELIÁ, 2006, p. 13). 
b) El problema de comparación interfamiliar

Corresponde ahora ocuparnos del siguiente de los «problemas» detectados. Siguiendo el mismo procedimiento que anteriormente, si quisiéramos aceptar la versión del legislador conforme se nos ofrece, deberíamos admitir que terrorismo y delincuencia sexual son, en todos los casos, grupos delictivos más graves que la delincuencia contra la vida o la delincuencia doméstica y de género. Esta idea no puede convencer como esquema general en tanto que resulta contradictorio tanto a nivel de comparación entre categorías (piénsese en considerar más grave atentar contra la libertad e indemnidad sexuales que contra la vida, en términos generales), como de comparación entre tipos de distintas familias. Si la gravedad puede contribuir en este punto, debe hacerlo en ponderación con otros factores o desde un concepto de gravedad distinto del estrictamente jurídico penal. Como en la sección anterior, este es un resultado razonable en la medida en que no hubiera tenido sentido emplear la gravedad del hecho como criterio exclusivo para otra cosa que no fuera medir la culpabilidad y jerarquizar en función de la misma, de lo cual ya se encarga ampliamente el Código sin necesidad de tener la peligrosidad en consideración.

Pasando a la probabilidad, ¿puede asumirse que todos los delitos incorporados en 2010 implican una mayor tendencia a reincidir que los incorporados en 2015? Si hemos de fiarnos del legislador, nuevamente tendríamos que considerar que así es, y hasta cierto punto bien podría ser el caso que el legislador considerara que los terroristas y delincuentes sexuales constituyen un subgrupo con mayor propensión a la repetición que los homicidas y los maltratadores. Cuestión distinta es que esta imagen revista o no un carácter de mito sociocultural en el que el legislador cae y perpetúa, cuestión que el presente escrito no puede abordar pero que ha sido ensayada por otros autores ${ }^{82}$. Con todo, es cierto que no queda claro por qué iba a considerar más probable la reincidencia de un terrorista que la de un maltratador y a su vez equiparable a la del delincuente sexual, por poner un ejemplo. Si decidimos aceptar esta interpretación tendremos que resignarnos ante la idea de que el legislador puede haber atribuido, de manera muy poco satisfactoria en cuanto a sus fundamentos, un mayor riesgo de reincidencia a los tipos de 2010, por exiguo o ilógico que pueda llegar a resultar.

En este caso, combinar una ponderación de gravedad y probabilidad de reincidencia nos deja prácticamente con idénticas dudas a la hora de comprender la «jerarquía de peligrosos» trazada por el legislador. El escrutinio de la ley no nos permite saber si las figuras introducidas en 2010

82 Ver, por ejemplo: DouARd (2008); RAmos VÁzQuez (2012). Ver también, en materia de delincuentes sexuales (especialmente con víctimas menores) y su construcción como «demonios populares», VAN DER WOLF (2016), pp. 40-41. 
reciben un tratamiento más restrictivo por ser más graves $y$ llevar aparejado mayor riesgo de reincidencia en la mente del legislador, si existe mayor peso de cualquiera de los criterios sobre el otro, o si el legislador es capaz siquiera de hacerse una idea ${ }^{83}$ acertada del riesgo de reincidencia para cada "familia» delictiva (si es que esto es mínimamente inteligible).

Por este motivo no podemos extraer conclusiones definitivas sobre la pauta seguida al atribuir un régimen más constrictivo a los delitos introducidos en 2010, al menos no sobre la base de los componentes que hemos escogido manejar (y en el sentido en que lo hemos hecho). La única pista interpretativa rescatable del texto legal procede del apartado vigesimosegundo del Prólogo a la LO 1/2015, en la que se introducen los nuevos tipos dentro del marco de la libertad vigilada. En dicho apartado, el legislador empieza explicando que "En materia de violencia de género y doméstica, se llevan a cabo algunas modificaciones para reforzar la protección especial que actualmente dispensa el Código Penal para las víctimas de este tipo de delito", continuando dos párrafos más abajo con "Además, se amplía el ámbito de la medida de libertad vigilada (...) [que] también se podrá imponer en todos los delitos contra la vida, y en los delitos de malos tratos y lesiones cuando se trate de víctimas de violencia de género y doméstica.»

En consecuencia, y a la vista del proceder argumentativo, la duda es la siguiente: ¿supone la equiparación de la respuesta en las categorías de delitos contra la vida y violencia doméstica y de género el resultado de proceder de una misma intención político criminal dirigida a incrementar la constricción penal para la criminalidad machista en sus distintas vertientes? ¿Debemos entender, por tanto, que el legislador piensa realmente en el homicidio/asesinato de género? Si así fuera, tendríamos una explicación plausible para las discrepancias interfamiliares que hemos resaltado: las tipologías introducidas en 2010 y en 2015 responderían a propósitos político criminales bien diferenciados que han influido en la concreta cristalización del régimen de libertad vigilada articulado en cada caso.

Así, aún a riesgo de resultar por el momento apresurado, podríamos ensayar con parte de la doctrina que, a través de la reforma efectuada en 2010, el legislador ha hecho uso del instrumento para regular una peligrosidad que se asemeja a una declaración de alteridad, al señalamiento de peligrosos-enemigos ${ }^{84}$. Con su segunda incursión, en cambio, el ob-

83 Algunos seguramente añadirían que ni siquiera es seguro que el legislador pretenda de ninguna manera hacerse una idea acertada del riesgo de reincidencia asociado a cada una de sus categorías, como viene implícito en la acusación de simbolismo que en ocasiones ha recibido la regulación de la libertad vigilada (VÁZQUEZ GonZÁLEZ, 2013, p. 264).

${ }^{84}$ No resulta sorprendente, pues, que la mayoría de artículos doctrinales específicamente orientados a trazar paralelismos entre la libertad vigilada y el llamado Derecho penal del enemigo hayan comentado la reforma de 2010. Ver, por ejemplo: BENítez ORTúZAR (2011), Jiménez Martínez (2012); Ya aludía a ello Boldova PaSAMAR (2009), en relación con el Anteproyecto de 2008.

(C) UNED. Revista de Derecho Penal y Criminología, 3. Época, $n .^{\circ} 20$ (2018) 
jetivo parece haber sido extender el uso de la peligrosidad para hacerla eficaz contra un problema totalmente distinto y mucho más relacionado con la familiaridad que con la «otredad», como es el de la violencia machista. Las implicaciones de esta interpretación son significativas: a) a nivel técnico, el método grosso modo empleado de nuevo por el legislador genera un considerable desbarajuste de proporcionalidad que degrada la coherencia interna del Código penal de manera inexplicable, b) sustancialmente, el legislador transmite (implícitamente) también un mensaje sobre cuál es su imago mentis sobre los criminales peligrosos: por una parte, están los auténticos peligrosos, los representantes penales de lo monstruoso ${ }^{85}$, sobre quienes es necesario desplegar un sistema recrudecido de supervisión en libertad. Por otro, está el colectivo de los «maltratadores», quienes reciben automáticamente una consideración de menor peligrosidad (recuérdese, incluso un asesinato no podría implicar más de 5 años de libertad vigilada) pero, paradójicamente, son considerados tácitamente todos como potenciales homicidas (a la vista de que el 140 bis, el 156 ter y el 173.2 in fine $\mathrm{CP}$ responderían a la misma racionalidad y se dirigirían frente al mismo colectivo de sujetos, sobre los que se arbitra una respuesta también idéntica). Desde este punto de vista, la «jerarquía de peligrosos» pasa a cobrar sentido, si no jurídico penal, sí a nivel interpretativo, y donde antes había irracionalidad ahora aparece una dicotomía: la del peligroso que es totalmente otro, frente al peligroso que está en nosotros ${ }^{86}$.

c) El problema de comparación intrafamiliar

Esta última sección resulta más directa en su abordaje. Como observación previa, cabe apuntar que, a nivel intrafamiliar, requieren especial atención los casos regulados bajo la LO 5/2010, pues son los únicos en que la ley prefija una suerte de gradación en la peligrosidad (o, más bien, en la imposición de la libertad vigilada). Por lo que respecta a las familias delictivas de 2015, la situación es más acorde con lo que sería de esperar en términos de peligrosidad y medidas de seguridad, en tanto que el carácter facultativo de la imposición de la medida abre la puerta a un juicio individualizado. En tal caso, no se emplea un criterio u otro para distinguir dentro de las familias típicas, trasladando la responsabilidad de esta labor al juzgador y los expertos de que se sirva ${ }^{87}$.

85 Ver sobre el particular: DouARD (2008), RAMOs VÁZQUEZ (2012); SimON (1998).

86 En proximidad a la distinción efectuada por GARLAND (1996, pp. 461-463) entre "criminología del sí mismo» (criminology of the self) y "criminología del otro» (criminology of the other).

87 Y aunque es cierto que el legislador amalgama tipos bien distintos dentro del mismo modelo de respuesta, como resalta SALAT PAISAL (2016, p.176) en el caso de los delitos contra la vida, la influencia de esta técnica «categorial» viene en buena medida contrapesada por el carácter facultativo que ostenta la libertad vigilada en los casos introducidos por la reforma de 2015 .

(C) UNED. Revista de Derecho Penal y Criminología, 3. ${ }^{a}$ Época, n. 20 (2018) 
Regresando, pues, a los supuestos indicados, la gravedad del hecho emerge esta vez como un criterio importante en las distinciones que el legislador ha tenido a bien hacer entre peligrosos. Por un lado, a la gravedad del delito (o de la pena, para terrorismo) viene vinculada la duración de la libertad vigilada de suerte que quedan establecidos dos tramos: para casos menos graves, de 1 a 5 años; para casos graves, de 5 a 10 años. Por otro lado, en el caso de delincuentes primarios, la menor gravedad es condición necesaria de modo que, sin este requisito (junto con el resto), no se puede aspirar a dejar de imponer la medida de seguridad. Más allá de este punto su utilidad decae y no nos permite discriminar entre tipos concretos, particularmente en el caso de que fueran ambos graves o menos graves.

Cabe por ello constatar que el criterio categorial de peligrosidad sigue imperando y tan sólo permite ciertas modulaciones de carácter general que se aplican por igual a cada uno de los tipos separándolos en graves y menos graves. Con todo, resulta ilustrativo que la gravedad del hecho haya sido empleada para decidir sobre la duración de la libertad vigilada, como si de la determinación de la pena se tratara (y a lo cual viene a añadirse la existencia de mínimos de cumplimiento). Por tanto, parece razonable entender que existe, al menos en la mente del legislador, una relación bastante directa entre gravedad del hecho y peligrosidad, de suerte que si a los autores de delitos graves se les sigue durante más tiempo es porque su peligrosidad puede también prolongarse más, siendo esto inferido de lo primero (en una interpretación al pie de la letra de lo expuesto).

Llegados a este punto, a la probabilidad de reincidencia le queda un margen de influencia reducido, pero puede resultar interesante para abordar los dos extremos que la ley produce: en el extremo de menor gravedad, con la cláusula del delincuente primario, el legislador hace específica mención no sólo a la gravedad del hecho, sino a que se atenderá a la «menor peligrosidad». Visto que ya ha dado cuenta anteriormente de la gravedad al prefigurarla como supuesto constitutivo de la cláusula, parece razonable entender que cuando habla de menor peligrosidad se está refiriendo al segundo de los aspectos, a saber, el riesgo de reincidencia futura. Este apartado ejemplifica un uso conjunto de los componentes en el que al juicio pronóstico se le concede valor discriminante a la hora de diferenciar entre primarios peligrosos y no peligrosos ${ }^{88}$. Nuevamente,

${ }_{88}$ Téngase en cuenta, en caso de no haber quedado claro durante las páginas precedentes, que en realidad estamos manejando constantemente dos conceptos de peligrosidad. El foco del presente texto se dirige hacia una acepción amplia o "abstracta» de peligrosidad que se deriva fundamentalmente del examen de la ley y extiende sus efectos de manera general. Sin embargo, en el fragmento que comentamos, cuando se hace referencia a la «menor peligrosidad», se está indicando la menor peligrosidad concreta del sujeto, valorada individualmente. Por eso en un caso como este se «valora la peligrosidad de los peligrosos», pues lo que se hace es examinar el riesgo concreto que representa un sujeto que la ley ha clasificado ex ante como peligroso en virtud del criterio categorial repetidamente mencionado. 
la gravedad ocupa un papel protagonista en cuanto que condición necesaria para poder valorar hasta qué punto el peligro posee una entidad suficiente. Mientras, dicha valoración individualizada aparece casi más como una «medida prudencial» tendente a garantizar la no peligrosidad, una suerte de salvaguarda para los limitados casos en que quepa la posibilidad de emplear la discrecionalidad judicial para no imponer medida asegurativa alguna.

Pasando al extremo de mayor gravedad, en cambio, procede volver a examinar esta peculiar amalgama según la cual una medida preventiva se dilata en función de la gravedad del hecho cometido, cuestión que debe recibir una explicación mínimamente satisfactoria si ha de asumirse que culpabilidad y peligrosidad hablan de cosas distintas. Como seguramente aquí no estemos en situación de generar un motivo convincente para la técnica legislativa empleada, nos limitaremos a llevarla a sus últimas consecuencias. La vinculación entre formas delictivas graves y supervisión prolongada nos permite intuir que en estos casos el legislador diseña su intervención frente a los autores de los delitos que más repulsa y alarma generan ${ }^{89}$, autores sobre quienes exige una especial precaución. Esta especial precaución posee la característica de poder prolongarse hasta los diez años, lo cual nos permite hablar de una expectativa de reincidencia a largo plazo ciertamente alejada de los lapsos que tiende a preferir la literatura en materia de valoración del riesgo de violencia. Si además consideramos, como se ha apuntado con anterioridad, que el legislador ha obrado pensando en los prototipos más graves de criminalidad, entonces tendríamos que pensar que, a los 10 años de libertad vigilada, cabe añadir al menos otra década de cumplimiento penitenciario (es decir, 20 años de peligrosidad «latente»). En este y otros ejemplos más exagerados ${ }^{90}$ vemos insinuarse una forma de concebir la probabilidad de reincidencia tan prolongada que bien podríamos entender que el legislador reintroduce, sin expresarlo, ideas de cronicidad e irrecuperabilidad aplicadas ciertos delincuentes específicos.

En suma, hemos podido ver que, para las distinciones dentro de una misma familia, el legislador ha articulado algunos criterios que, sin permitir hilar muy fino, hacen posible una diferenciación entre los

89 Por mucho que omita en el proceso a los autores de delitos de asesinato, candidatos habituales de estas y otras formas de medidas asegurativas y/o punitivas. Esto bien puede deberse a lo comentado más arriba en relación con el tipo de homicida/asesino en que pensaba el legislador cuando introdujo la reforma.

90 Pensemos, obviando por un instante la prisión permanente revisable, que se alcanza el máximo de 40 años de pena de prisión. Sobre esto, añadimos 10 años más de libertad vigilada. Si luego asumimos que la condena llega con unos 25 años tenemos que, para cuando llegue el momento de «disfrutar de la libertad» nuestro delincuente peligroso contará con unos nada desdeñables 75 años (vividos en su mayoría dentro del medio penitenciario). Queda delineada una suerte de forma perfecta de control social que comienza con la prisión y acaba en el geriátrico. 
tipos incorporados según sean graves o menos graves. Distinción que puede venir apoyada adicionalmente, en los casos de primariedad, por la consideración de una eventual menor peligrosidad. Consecuentemente, a pesar de las dificultades interpretativas, sí puede afirmarse con cierta seguridad que el legislador, conforme se aproximaba al caso concreto ${ }^{91}$, ha hecho un mayor uso de los dos componentes que hemos seleccionado. Con todo, no es menos cierto que el sistema que se obtiene como resultado sigue gozando de un marcado automatismo que no se compadece demasiado bien con la naturaleza de medida de seguridad de la libertad vigilada.

Resulta bien interesante, en cualquier caso, observar cómo el régimen establecido permite que asome una concepción de "peligrosidad crónica» que quizás no esperaríamos encontrar en el ordenamiento hoy por hoy. Además, el peso de la gravedad del hecho cometido en la determinación de la duración de la libertad vigilada nos expone a una situación problemática: en los casos en que la respuesta penal compagina una medida de seguridad que se modula por la culpa (en el sentido indicado), y una duración extensiva de la prevención en libertad, el legislador produce un juicio de "cronicidad» que se origina como consecuencia de la mayor gravedad del delito y a través de un cauce imperativo. De esta manera, ser considerado peligroso pasa a deducirse de la pena y se añade a esta, como un anexo cuya aplicación efectiva ya se decidirá en su momento tras una prolongada pena de prisión. El retrato emergente es, en estos casos, el del presuntamente irrecuperable, peligroso hasta que se demuestre lo contrario.

\section{Síntesis}

De todo lo expuesto a lo largo de las líneas precedentes podemos extraer algunas ideas clave así como ensayar una interpretación aproximada de la cuestión. Procediendo en orden:

En primer lugar, un juicio combinado de probabilidad y gravedad se intuye en la determinación de qué categorías son incluidas dentro de los peligrosos legalmente definidos. En términos generales, estas tienden a revestir cierta gravedad y, además, su reincidencia aparece como probable al menos en medida suficiente como para sopesarse con la gravedad del delito. Ahora bien, esta óptica no es plenamente satisfactoria y apunta a la existencia de otras variables complejizadoras o, incluso, una con-

91 Una cuestión que queda abierta es la de si el legislador incrementa su uso de la «racionalidad jurídica» conforme el objeto a regular se vuelve más concreto, más cercano a la práctica, reservándose mayores cotas de discrecionalidad para aquellas decisiones más abstractas y abiertas a la dimensión política de la política criminal. 
cepción de la peligrosidad menos inspirada en la episteme jurídico penal que en la doxa sociocultural a la que trata de dar respuesta.

A la hora de distinguir entre 2010 y 2015, la situación es poco clara en general y nos obliga prácticamente a aceptar el estado de cosas como representativo del concepto de peligrosidad empleado por el legislador: delincuentes sexuales y terroristas son de facto considerados como más peligrosos que homicidas y maltratadores en nuestro ordenamiento jurídico. La búsqueda de una explicación que dé cuenta de esta diferencia, sin embargo, puede comenzar a atisbarse en las propias motivaciones de las reformas, donde hemos visto que todos los cambios efectuados por la LO 1/2015 en materia de libertad vigilada se subsumen dentro de una declarada intención de seguir haciendo frente a las formas de violencia vinculadas al machismo. Bien podría ser que esta no fuera la única razón para la regulación que tenemos pero, como se ha podido ver, su empleo como instrumento interpretativo arroja interesantes consecuencias para la comprensión de esta «dualidad» de libertades vigiladas. Este enfoque nos ha permitido, en el proceso, otear más en profundidad la imagen mental que nuestro legislador se hace de quiénes son sus peligrosos y qué características reúnen, a través del tratamiento diferenciado que les dispensa.

Por último, dentro de las familias de terrorismo y delincuencia sexual, nuestros dos componentes (nuevamente, la percepción de la gravedad del hecho cometido, y una expectativa sobre la probabilidad de reincidencia específica) intervienen como recursos moduladores de la intervención a través de la libertad vigilada, y esto en dos situaciones: extendiendo su duración frente a los casos más graves, y permitiendo su inaplicación en los más leves. El examen más detallado de esta «bifurcación» ${ }^{92}$ de los peligrosos nos ha permitido a su vez extraer algunas notas interpretativas adicionales sobre la naturaleza de la libertad vigilada como instrumento jurídico penal así como, nuevamente, la construcción mental del peligroso que ha orientado al legislador. Por un lado, se ha puesto de manifiesto que, para los tipos de 2010, la libertad vigilada tiene por lo menos tanto que ver con el concepto de castigo como con el concepto de prevención de la delincuencia futura. Y esto por el peso que ostenta la gravedad del hecho cometido en la determinación de la extensión de la medida de seguridad, relegando la probabilidad de reincidencia a un segundo plano, casi como una última precaución en caso de plantearse la posibilidad de la inaplicación. Por otro, el tratamiento dispensado a los «criminales más peligrosos» deja entrever, en la extensión potencial de la supervisión penal prevista para tales sujetos, un concepto de peligrosidad afín a los conceptos ya clásicos de cronicidad e irrecuperabilidad.

92 Concepto tomado de Stanley COHEN (1985), p. 147. 
Más en general, la envergadura de los puntos ciegos que un análisis como el efectuado evidencia, refuerza la idea nada extraña de que el legislador no se guía exclusivamente por criterios de lógica jurídico penal en su toma de decisiones sino que, en el mejor de los casos, los combina con otras apreciaciones extrajurídicas que se adivinan como variables de enorme peso en la construcción de la peligrosidad criminal.

\section{Conclusiones}

Mediante la labor precedente se ha tratado de indagar en la construcción del delincuente peligroso manejada por el legislador a través del examen e interpretación de los instrumentos normativos destinados manifiestamente a tal efecto. Este método ha permitido extraer algunas de las notas características de este nuevo «sujeto jurídico penal» tal como ha podido ser imaginado por el legislador. La condición de partida para ello ha sido tomar como base la palabra del legislador y adjudicarle una coherencia interna que frecuentemente la doctrina se ha encargado de poner en cuestión. Esto no se considera como una debilidad del enfoque empleado si no, al contrario, una consecuencia del objetivo ambicionado por la investigación, que pasa por tomar la ley penal como un hecho social con carácter discursivo, que lleva ínsito un mensaje y, cómo no, una serie de consecuencias prácticas. De ahí se predica que la constitución de una legislación sobre peligrosidad no puede sino constituir en el proceso una definición de dicho sujeto peligroso que, en el ínterin, le otorga entidad, cuando menos, como indicador de la forma en que el peligro criminal es entendido en una sociedad y un periodo dados.

El examen de la construcción legal del delincuente imputable peligroso ha permitido no sólo hacer manifiesto algo que frecuentemente sólo queda latente (los motivos o ideas que orientan la labor del legislador penal), sino componer un retrato interesante de la peligrosidad criminal. Como hemos visto, esta funciona de forma categorial en nuestra legislación. De ahí derivan dos consecuencias: en primer lugar, hace altamente trascendente el proceso de selección empleado por el legislador al ser este el factor determinante de la inclusión o no dentro del subconjunto de los «delincuentes imputables peligrosos»; por otra parte, otorga a las categorías delictivas escogidas una función de «etiqueta» en tanto que extienden sus efectos a toda su familia típica con indiferencia de las distinciones sustanciales que quepa hacer en uno y otro caso (la «presunción de peligrosidad» arbitrada en los casos de terrorismo y delincuencia sexual no hace sino enfatizar este punto). Adicionalmente, puede inferirse con cierto grado de seguridad que cada subconjunto de delincuentes imputables peligrosos viene referida a un prototipo (el maltratador, el violador, el terrorista...) que constituye el patrón de intervención para todos los demás tipos subsumidos en su interior, y que retrata una metodología reguladora basada en «el peor de los casos».

(C) UNED. Revista de Derecho Penal y Criminología, 3. ${ }^{a}$ Época, $n .^{\circ} 20$ (2018) 
Con todo, se vislumbra que, a pesar de este criterio generalizador, para el legislador no todos los peligrosos son iguales, lo cual arroja una serie de problemas que hemos tratado de examinar con objeto de extraer de ellos el mayor número de indicios posibles sobre el delincuente peligroso legal. Como consecuencia, se ha podido observar que seguramente el legislador emplea un concepto de peligrosidad hasta cierto punto complejo y basado en una ponderación desigual de criterios como la gravedad del hecho y la probabilidad de reincidencia. El empleo de ambos componentes como herramientas investigativas ha hecho posible inferir otras piezas conceptuales con las que el legislador parece haberse hecho una idea de qué es la criminalidad peligrosa y cómo se articula. Esto contribuye a desentrelazar un tanto la interpretación de la normativa y a vincularla, no sólo con intenciones político criminales, sino también con connotaciones y preconcepciones de la peligrosidad criminal.

El carácter implícito de muchos de los aspectos examinados ha propiciado la imagen de irracionalidad y aleatoriedad que se ha atribuido al legislador. Al tratar de arrojar luz sobre tales aspectos se ha contribuido a problematizar un tanto esta impresión. Y aunque es cierto que de lo observado no se deduce que la técnica legislativa seguida sea razonable ni apropiada, sí aparece como orientada por una multiplicidad de influencias más allá de lo jurídico que tienden a insertar, para bien o para mal, al legislador dentro de la complejidad de la cultura a la que pertenece.

Circunscribiendo de nuevo el enfoque, podemos apreciar que la trayectoria seguida por el legislador no se corresponde exactamente con el peso connotativo asociado al modelo de «Derecho penal de la peligrosidad/de autor» ni, de hecho, armoniza demasiado bien con los planteamientos del positivismo criminológico, ambos focos de inquietud de la doctrina cuando se intuye una "deriva» del sistema punitivo en un sentido o en otro. Por un lado, la forma en que el legislador ha designado a los sujetos peligrosos no entroniza al autor del delito como objeto protagónico sobre el que ha de modularse la respuesta jurídico penal en función de lo que es. Correlativamente, tampoco se opta por constituir de forma expresa una alianza entre los operadores jurídicos y los cuerpos de expertos en «ciencias del hombre». Desde luego, no es que estos elementos no estén presentes en un momento $\mathrm{u}$ otro (como hemos visto, de forma directa o indirecta la peligrosidad es valorada como presupuesto para hacer efectivas las medidas de seguridad), pero ciertamente nos hemos alejado considerablemente de lo planeado por el Anteproyecto de 2012, auténtico hito no cristalizado en la elaboración de un sistema dualista completo.

Ello no obstante, por mucho que el legislador haya optado por una intervención más bien aguda que omnicomprensiva sobre la peligrosidad (algo que puede ser valorado positivamente), la forma en 
que ha efectuado dicha tarea resulta altamente significativa de las prioridades político criminales así como del imaginario (justificado o no) que las instruye. En este sentido, parece claro que la transgresión de determinados límites (la comisión de ciertos tipos de delitos) ha adoptado la función de singularizar a cierto tipo de autores frente al resto de delincuentes, haciéndolos objeto de una extensión del control estatal. Esta forma de garantizar la seguridad pública, sin embargo, adopta un criterio abarcador en el que la cuestión de la definición de los riesgos en función de su probabilidad o seriedad, aunque existente, queda hasta cierto punto desbancada por otro proceso paralelo de ponderación del nivel de tolerancia ante dichos riesgos. Este proceso de balanceo de la "carga de riesgo" que debe soportar la sociedad como contrapartida a la libertad de sus miembros parece haber sufrido alteraciones recientes que han contribuido a que cualquier peligro posible (procedente de los sujetos designados como peligrosos) se haya convertido en prácticamente inadmisible. Esta rebaja del umbral de tolerancia parece instituirse como factor preponderante en el abordaje reciente de la peligrosidad criminal y coincide con un recrudecimiento de las demandas de seguridad que el legislador está decidido a satisfacer. El carácter más complejo y socioculturalmente mediado de estas apreciaciones impide, a pesar de todo, su deducción de la letra de la ley, motivo por el que han de quedar apuntadas a título meramente indiciario, aunque ya sea bien conocido que el legislador de los últimos años sin duda ha asumido como labor esencial fortalecer la confianza en la Justicia a través de sucesivas expansiones punitivas.

\section{Bibliografía}

AcAle SÁNCHEZ, M.: «8.4. medidas de seguridad». En F. J. Álvarez García (Dir.), y J. Dopico Gómez-Aller (Coord.), Estudio crítico sobre el anteproyecto de reforma penal de 2012. Valencia: Tirant Lo Blanch, 2013, pp. 415-453.

Acale SÁnchez, M.: «Nuevos presupuestos para la imposición de penas y medidas de seguridad». En A. I. Pérez Cepeda, y M. C. Gorjón Barranco (Eds.), El proyecto de reforma del código penal de 2013, a debate. Salamanca: Ratio Legis, 2014, pp. 91-124.

Acale Sánchez, M., Álvarez García, F. J., Borja Jiménez, E., Demetrio Crespo, E., Dopico Gómez-Aller, J., Etxebarria Zarrabeitia, X., García Rivas, N., Manso Porto, T., y Marambio Avaria, A. «8.1. Custodia de seguridad: Arts. 96.2, 101, 102.3 y 103.2 CP». En F. J. Álvarez García (Dir.), y J. Dopico Gómez-Aller (Coord.), Estudio crítico sobre el anteproyecto de reforma penal de 2012. Valencia: Tirant lo Blanch, 2013, pp. 395-404. 
ANDRÉS-PueYo, A.: «Peligrosidad criminal: Análisis crítico de un concepto polisémico». En E. Demetrio Crespo (Dir.), y M. Maroto Calatayud (Coord.), Neurociencias y Derecho penal. Madrid: Edisofer, 2013, pp. 483-504.

Armaza Armaza, E. J. El tratamiento penal del delincuente imputable peligroso. Granada: Comares, 2013.

Armstrong, G. S., \& FreEman, B. C.: «Examining GPS monitoring alerts triggered by sex offenders: The divergence of legislative goals and practical application in community corrections». Journal of Criminal Justice, 2011, 39(2), pp. 175-182.

BEARD, J.: Sentences of imprisonment for public protection. Bonn: House of Commons Library, 2014.

Benítez ORTúZAR, I. F.: «La nueva «medida de seguridad» de «libertad vigilada» aplicable al sujeto imputable tras el cumplimiento de la pena privativa de libertad. La admisión de los postulados del «Derecho penal del enemigo» para la LO 5/2010». Cuadernos de Política Criminal, 2011, 103, pp. 95-132.

Blanco Cordero, I., y Doval Pais, A.: «La extranjería como factor de discriminación de los condenados a penas de prisión». En L. R. Ruiz Rodríguez (Ed.), Crimen organizado y extranjería en España y marruecos. Valencia: Tirant lo Blanch, 2013, pp. 51-84.

Boldova Pasamar, M. Á.: «Consideraciones político-criminales sobre la introducción de la libertad vigilada». ReCrim, 2009, pp. 290-315.

BORJA JIMÉNEZ, E.: «Custodia de seguridad, peligrosidad postcondena y libertad en el estado democrático de la era de la globalización: Una cuestión de límites». Revista General De Derecho Penal, 2012, 18, pp. $1-57$.

BorJA JimÉnEZ, E.: «Peligrosidad postcondena, intervención punitiva y estado de derecho». En E. Orts Berenguer, A. Alonso Rimo \& M. Roig Torres (Eds.), Derecho penal de la peligrosidad y prevención de la reincidencia. Valencia: Tirant lo Blanch, 2015, pp. 151-260.

BRANDARIZ GARcíA, J. Á.: «La difusión de lógicas actuariales y gerenciales en las políticas punitivas». InDret, 2/2014, pp. 1-27.

CÁmara Arroyo, S.: «La libertad vigilada: De la ley penal del menor al ordenamiento penal de adultos». RJUAM, 2012, 25, pp. 71-106.

Cancio Meliá, M.: «De nuevo: ¿»Derecho penal» del enemigo?» En M. Cancio Meliá, y C. Gómez-Jara Díez (Eds.), Derecho penal del enemigo: El discurso penal de la exclusión. Madrid: Edisofer, 2006, pp. 341-482.

Centre D’estudis Jurídics i Formació Especialitzada.: Delitos sexuales y reincidencia. Barcelona, 2009.

Centre D’estudis Jurídics i Formació Especialitzada.: Tasa de reincidencia penitenciaria 2014. Barcelona, 2015. 
CEREzo MIR, J.: «Reflexiones críticas sobre algunas manifestaciones de la moderna tendencia a incrementar el rigor en la exigencia de responsabilidad criminal». Revista Penal, 2008, 22, pp. 16-21.

CoHen, S.: Visions of social control (1. publ. ed.). Cambridge: Polity Press, 1985.

DíEz RIPOLLÉs, J. L.: «De la sociedad del riesgo a la seguridad ciudadana: un debate desenfocado». RECPC, 2005(7), pp. 1-37.

DouARD, J.: "Sex offender as scapegoat: The monstrous other within». New York Law School Law Review, 2008, 53(1), pp. 31-53.

ERICSON, R. V.: Crime in an insecure world. Cambridge, UK; Malden, MA: Polity, 2007.

García ArÁn, M.: «¿Penas o medidas?: Del garantismo a la confusión». En P. de la Cuesta Aguado, L. R. Ruíz Rodríguez, M. Acale Sánchez, E. Hava García, M. J. Rodríguez Mesa, G. González Agudelo, I. Meini Méndez y J. M. Ríos Corbacho (Coords.), Liber Amicorum. Estudios Jurídicos en Homenaje al Prof. Dr. Dr. h.c. Juan M. ${ }^{a}$ Terradillos Basoco.Valencia: Tirant lo Blanch, 2018, pp. 393-405

García Rivas, N.: «Los «anormales» y su discriminación penal». En P. de la Cuesta Aguado, L. R. Ruíz Rodríguez, M. Acale Sánchez, E. Hava García, M. J. Rodríguez Mesa, G. González Agudelo, I. Meini Méndez y J. M. Ríos Corbacho (Coords.), Liber Amicorum. Estudios Jurídicos en Homenaje al Prof. Dr. Dr. h.c. Juan M. ${ }^{a}$. Terradillos Basoco. Valencia: Tirant lo Blanch, 2018, pp. 377-390.

García RIVAS, N. «La libertad vigilada y el Derecho penal de la peligrosidad». En E. Demetrio Crespo (Dir.), y M. Maroto Calatayud (Coord.), Neurociencias y Derecho penal. Madrid: Edisofer, 2013, pp. 601-628

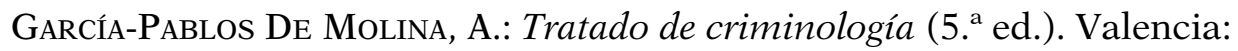
Tirant lo Blanch, 2014.

GARLAND, D.: «The limits of the sovereign state: Strategies of crime control in contemporary society». The British Journal of Criminology, 1996, 36(4), pp. 445-471.

Gracia Martín, L. "Sobre la legitimidad de las medidas de seguridad contra delincuentes imputables peligrosos en el Estado de Derecho». En C. García Valdés, Valle Mariscal De Gante, Margarita, A. R. Cuerda Riezu, M. Martínez Escamilla y R. Alcácer Guirao (Coords.), Estudios penales en Homenaje a Enrique Gimbernat. Madrid: Edisofer, 2008, pp. 975-1004.

Grupo de Estudios de Política CRiminal. Alternativas al sistema de sanciones penales: Nuevas penas y medidas restrictivas de derechos. Valencia: Tirant lo Blanch, 2012.

Hebenton, B., y Seddon, T.: «From dangerousness to precaution». The British Journal of Criminology, 2009, 49(3), pp. 343-362. 
Herrero, O.: «¿Por qué no reincide la mayoría de los agresores sexuales?». Anuario de Psicología Jurídica, 2013, 23(1), pp. 71-77.

Horgan, J., y BRADDOCK, K.: «Rehabilitating the terrorists?: Challenges in assessing the effectiveness of de-radicalization programs». Terrorism and Political Violence, 2010, 22(2), pp. 267-291.

Huerta Tocildo, S.: «Esa extraña consecuencia del delito: La libertad vigilada». Libro homenaje al profesor Luis Rodríguez Ramos. Valencia: Tirant lo Blanch, 2013, pp. 117-137.

JimÉnez Martínez, C.: «La libertad vigilada en el C.P. de 2010: especial mención a la libertad vigilada para imputables peligrosos». Revista de derecho penal y criminología, 2014, 7, pp. 13-50.

JoRge BARREIRO, A. «Reflexiones sobre la problemática actual y el futuro de las medidas de seguridad criminales: Su regulación en el Derecho penal español y en el Derecho comparado». En D. M. Luzón Peña (Dir.), Derecho penal del Estado Social y Democrático de Derecho. Libro Homenaje a Santiago Mir Puig. Madrid: La Ley, 2010, pp. 599-660.

LEal Medina, J.: «El concepto de peligrosidad en el derecho penal español. Proyección legal y alcance jurisprudencial. Perspectivas actuales y de futuro». Diario La Ley, 2011, 7643, pp. 1-12.

LiN, J., Grattet, R., y Petersilia, J.: «Back-end sentencing and reimprisonment: Individual, organizational, and community predictors of parole sanctioning decisions». Criminology, 2010, 48(3), pp. 759-795.

Llobet ANGLí, M.: «Capítulo 25. tenencia, tráfico y depósito de armas o municiones, organizaciones y grupos criminales y delitos de terrorismo». En J. M. Silva Sánchez, y N. Pastor Munoz (Eds.), El nuevo código penal. Comentarios a la reforma. Madrid: La Ley, 2012, pp. 671-724.

LoINAz, I.: Manual de evaluación del riesgo de violencia: Metodología y ámbitos de aplicación. Madrid: Ediciones Pirámide, 2017.

Manso Porto, T., Molina Blázquez, M. C., y Rodríguez Horcajo, D.: «8.2 custodia de seguridad: Enmienda subsidiaria de modificación». En F. J. Álvarez García (Dir.), y J. Dopico Gómez-Aller (Coord.), Estudio crítico sobre el anteproyecto de reforma penal de 2012. Valencia: Tirant Lo Blanch, 2013, pp. 405-412.

Manzanares Samaniego, J. L.: «La libertad vigilada». Diario La Ley, 2010, 7386, pp. 1-15.

Mapelli Caffarena, B.: «Nuevas tendencias penológicas: Hacia la penología del control». En P. de la Cuesta Aguado, L. R. Ruiz Rodríguez, M. Acale Sánchez, E. Hava García, M. J. Rodríguez Mesa, G. González Agudelo, I. Meini Méndez y J. M. Ríos Corbacho (Coords.), Liber Amicorum. Estudios Jurídicos en Homenaje al Prof. Dr. Dr. h.c. Juan M. ${ }^{a}$. Terradillos Basoco. Valencia: Tirant lo Blanch, 2018, pp. 427-440. 
MARAVER Gómez, M.: «Consideraciones político-criminales sobre el tratamiento penal de los delincuentes imputables peligrosos». RJUAM, 2015, 31(I), pp. 283-330.

Martín Aragón, M. M.: «La prisión permanente revisable: Crónica de una derogación anunciada». En P. de la Cuesta Aguado, L. R. Ruíz Rodríguez, M. Acale Sánchez, E. Hava García, M. J. Rodríguez Mesa, G. González Agudelo, I. Meini Méndez y J. M. Ríos Corbacho (Coords.), Liber Amicorum. Estudios Jurídicos en Homenaje al Prof. Dr. Dr. h.c. Juan M. ${ }^{a}$. Terradillos Basoco. Valencia: Tirant lo Blanch, 2018, pp. 441-454

Martínez Garay, L.: «La libertad vigilada: Regulación actual, perspectivas de reforma y comparación con la Führungsaufsicht del derecho penal alemán». Revista General De Derecho Penal, 2014, 22, pp. 1-74.

Murphy, E.: «Paradigms of restraint». Duke Law Journal, 2008, 57(c), pp. 1321-1411.

NAVARro FríAs, I.: «Psicopatía y medidas de seguridad: el caso de los psicópatas sexuales y la libertad vigilada tras la última reforma del Código Penal». Cuadernos de Política Criminal, 2011, 105, pp. 117-158.

NELLIS, M.: «Understanding the electronic monitoring of offenders in europe: Expansion, regulation and prospects». Crime, Law and Social Change, 2014, 62(4), pp. 489-510.

Nistal Burón, J.: «La nueva medida de «custodia de seguridad». Una respuesta complementaria frente a los delincuentes más peligrosos». Diario La Ley, 2013, 8035, pp. 1-9.

OTERo GonzÁlez, P.: «La libertad vigilada aplicada a imputables tras la reforma». Revista Del Ministerio Fiscal, 2015, 0, pp. 71-91.

Payne, B. K., y Demichele, M. T.: «Electronic supervision for sex offenders: Implications for work load, supervision goals, versatility, and policymaking». Journal of Criminal Justice, 2010, 38(3), pp. 276-281.

PRATT, J.: Governing the dangerous: Dangerousness, law, and social change. Sydney: The Federation Press, 1997.

Quintero Olivares, G.: «Monismo y dualismo. culpables y peligrosos». En E. Demetrio Crespo (Dir.), y M. Maroto Calatayud (Coord.), Neurociencias y Derecho penal. Madrid: Edisofer, 2013, pp. 651-668

Ramos VÁzQuez, J. A.: «Depredadores, monstruos, niños y otros fantasmas de impureza (algunas lecciones de Derecho comparado sobre delitos sexuales y menores)». Revista de Derecho Penal y Criminología, 2012, 8, pp. 195-227.

Rebollo VARgas, R.: «A vueltas con el derecho penal de la peligroridad». En P. de la Cuesta Aguado, L. R. Ruiz Rodríguez, M. Acale Sánchez, E. Hava García, M. J. Rodríguez Mesa, G. González Agudelo, I. Meini Méndez y J. M. Ríos Corbacho (Coords.), Liber Amicorum. Estudios

(C) UNED. Revista de Derecho Penal y Criminología, 3. Época, $n .{ }^{\circ} 20$ (2018) 
Jurídicos en Homenaje al Prof. Dr. Dr. h.c. Juan M. ${ }^{a}$. Terradillos Basoco. Valencia: Tirant lo Blanch, 2018, pp. 349-366.

Robles Planas, R.: ««Sexual predators». estrategias y límites del derecho penal de la peligrosidad». InDret, 2007, 4, pp. 1-27.

RoIG ToRRES, M.: «La reforma del código penal en materia de reiteración delictiva». In E. Orts Berenguer, A. Alonso Rimo y M. Roig Torres (Eds.), Derecho penal de la peligrosidad y prevención de la reincidencia. Valencia: Tirant lo Blanch, 2015, pp. 333-408.

Romeo Casabona, C. M.: Peligrosidad y Derecho penal preventivo. Barcelona: Bosch, 1986.

SÁez Díaz, Y., Montiel Juan, I., y Carbonell Vayá, E.: «De la peligrosidad a la valoración de la reincidencia: Métodos e instrumentos de evaluación». En E. Orts Berenguer, A. Alonso Rimo y M. Roig Torres (Eds.), Derecho penal de la peligrosidad y prevención de la reincidencia. Valencia: Tirant lo Blanch, 2015, pp. 105-147.

Salat Paisal, M.: La respuesta jurídico-penal a los delincuentes imputables peligrosos: Especial referencia a la libertad vigilada (1. ${ }^{\mathrm{a}}$ ed.). Cizur Menor, Navarra: Thomson Reuters Aranzadi, 2015.

SAlat Paisal, M.: «Regulación actual de la medida de seguridad de libertad vigilada y su aplicación por parte de los tribunales». Anuario da Facultade de Dereito da Universidade da Coruña, 2016, 20, pp. 161-187.

SÁNCHEz LÁZARO, F. G.: «Un problema de peligrosidad postdelictual: Reflexiones sobre las posibilidades y límites de la denominada custodia de seguridad». Revista Penal, 2004, pp. 142-165.

SANZ MoRÁN, Á J.: Las medidas de corrección y de seguridad en el derecho penal. Valladolid: Lex Nova, 2003.

SANZ Morán, Á J.: «La nueva medida de libertad vigilada: Reflexión político-criminal». En F. Munoz Conde, J. M. Lorenzo Salgado, J. C. Ferré Olivé, E. Cortés Bechiarelli y M. Á Núnez Paz (Eds.), Un derecho penal comprometido: Libro homenaje al Prof. Dr. Gerardo Landrove Díaz. Valencia: Tirant lo Blanch, 2011, pp. 997-1028.

SANZ-DíEz DE UlzurRun Lluch, M.: «Reincidencia, habitualidad y profesionalidad en las últimas reformas penales: especial referencia a la delincuencia patrimonial». Estudios penales y criminológicos, 2013, 33, pp. 97-148.

Serrano Gómez, A.: «Notas al Anteproyecto de Reforma del Código Penal español de octubre de 2012». Revista electrónica de ciencia penal y criminología, 2013, 15, pp. 1-18

SiLva Sánchez, J. M.: «¿Es la custodia de seguridad una pena?», InDret, 2010.

Silva Sánchez, J. M.: La expansión del derecho penal: Aspectos de la política criminal en las sociedades postindustriales (2. ${ }^{\text {a }}$ ed.). Buenos Aires: Edisofer, 2006. 
Silva SÁnchez, J. M.: «El retorno de la inocuización. el caso de las reacciones jurídico penales frente a los delincuentes sexuales violentos». En L. Arroyo Zapatero, y I. Berdugo Gómez de la Torre (Eds.), Homenaje al Dr. Marino Barbero Santos in memoriam. Cuenca: Ediciones de la Universidad de Castilla La Mancha, Ediciones Universidad de Salamanca, 2001, pp. 699-710.

Simon, J.: «Managing the monstruous: Sex offenders and the new penology». Psychology, Public Policy, and Law, 1998, 4, pp. 452-467.

Terradillos Basoco, J. Peligrosidad social y Estado de Derecho. Madrid: Akal, 1981.

TORRes Rosell, N.: «Libertad vigilada y seguimiento continuado de penados: Contenido e implicaciones político criminales». Revista electrónica de ciencia penal y criminología, 2012, 14, pp. 1-45.

URRUEla MoRA, A.: Las medidas de seguridad y reinserción social en la actualidad: Especial consideración de las consecuencias jurídico-penales aplicables a sujetos afectos de anomalía o alteración psíquica. Granada: Comares, 2009.

URruela Mora, A.: «¿Hacia un cambio de paradigma? la configuración de un derecho penal de la peligrosidad mediante la progresiva introducción de medidas de seguridad aplicables a sujetos imputables en las recientes reformas penales españolas». Cuadernos De Política Criminal, mayo 2015(115), 119-160.

VAN DER Wolf, M.: «Legal control on social control of sex offenders in the community: A european comparative and human rights perspective». Erasmus Law Review, 2016, 9(2), pp. 39-54.

VÁzouez GonzÁLEZ, C.: «Algunas cuestiones penales y criminológicas sobre la nueva medida de libertad vigilada». En F. J. Álvarez García, Cobos Gómez de Linares, Miguel Ángel, P. Gómez Pavón, A. Manjón-Cabeza Olmeda y A. Martínez Guerra (Eds.), Libro homenaje al profesor Luis Rodríguez Ramos. Valencia: Tirant lo Blanch, 2013, pp. 247-270.

ZAFFARONI, E. R.: «Los disfraces de la peligrosidad (la pena del delito común contra la propiedad)». En P. de la Cuesta Aguado, L. R. Ruiz Rodríguez, M. Acale Sánchez, E. Hava García, M. J. Rodríguez Mesa, G. González Agudelo, I. Meini Méndez y J. M. Ríos Corbacho (Coords.), Liber Amicorum. Estudios Jurídicos en Homenaje al Prof. Dr. Dr. h.c. Juan M. ${ }^{a}$. Terradillos Basoco. Valencia: Tirant lo Blanch, 2018, pp. 367-376.

Zugaldía EsPinar, J. M.: «Medidas de seguridad complementarias y acumulativas para autores peligrosos tras el cumplimiento de la pena». Revista de Derecho Penal y Criminología, 2009, 1, pp. 199-2012.

Zugaldía Espinar, J. M.: «8.7. medidas de seguridad». En F. J. Álvarez García (Dir.), \& J. Dopico Gómez-Aller (Coord.), Estudio crítico sobre el anteproyecto de reforma penal de 2012. Valencia: Tirant lo Blanch, 2013, pp. 481-484. 